\title{
Mechanisms Underlying Influence of Bioelectricity in Development
}

\author{
Laura Faith George and Emily Anne Bates* \\ Department of Pediatrics, University of Colorado School of Medicine, Aurora, CO, United States
}

To execute the intricate process of development, cells coordinate across tissues and organs to determine where each cell divides and differentiates. This coordination requires complex communication between cells. Growing evidence suggests that bioelectrical signals controlled via ion channels contribute to cell communication during development. Ion channels collectively regulate the transmembrane potential of cells, and their function plays a conserved role in the development of organisms from flies to humans. Spontaneous calcium oscillations can be found in nearly every cell type and tissue, and disruption of these oscillations leads to defects in development. However, the mechanism by which bioelectricity regulates development is still unclear. Ion channels play essential roles in the processes of cell death, proliferation, migration, and in each of the major canonical developmental signaling pathways. Previous reviews focus on evidence for one potential mechanism by which bioelectricity affects morphogenesis, but there is evidence that supports multiple different mechanisms which are not mutually exclusive.

Edited by:

Claudia Tanja Mierke, Leipzig University, Germany

Reviewed by: Javier Cervera, University of Valencia, Spain

Saak V. Ovsepian, University of Greenwich, United Kingdom

*Correspondence: Emily Anne Bates Emily.Bates@CUAnschutz.edu

Specialty section: This article was submitted to Cell Adhesion and Migration, a section of the journal Frontiers in Cell and Developmental Biology

Received: 07 September 2021 Accepted: 07 January 2022 Published: 14 February 2022

Citation:

George LF and Bates EA (2022) Mechanisms Underlying Influence of Bioelectricity in Development.

Front. Cell Dev. Biol. 10:772230. doi: $10.3389 /$ fcell.2022.772230
Evidence supports bioelectricity contributing to development through multiple different mechanisms. Here, we review evidence for the importance of bioelectricity in morphogenesis and provide a comprehensive review of the evidence for several potential mechanisms by which ion channels may act in developmental processes.

Keywords: bioelectricity, ion channels, signaling, signaling pathways, prolifieration, apoptosis

\section{INTRODUCTION}

The process by which a single fertilized egg develops into a multicellular organism is a remarkable feat of biology. For most plants and animals, the fertilized egg must undergo dozens of repeated divisions with various lineages of cells proliferating, migrating, and differentiating at exactly the correct times and places within 3D space to form the specialized tissues and organs of the adult organism. This process requires a vast amount of information to be transmitted and processed for the organism to form correctly, and yet this process occurs in every multicellular species.

Development is robust, with organisms and tissues able to withstand damage or induced errors during development and still ultimately develop correctly. This remarkable ability to develop correctly after perturbation can be seen in the development of twins. In the early stages of mammalian development embryos can be completely split into two, and each half can go on to produce a fully developed organism. This splitting can even occur spontaneously as late as 14 days post-fertilization in human embryos and result in the correct development of a set of twins (Hall, 2003). Thus, the process of development is not simply an unfolding of a single developmental pathway encoded rigidly within genetics. Developing organisms can also correct early damage. The imaginal discs in developing Drosophila can regenerate after damage or ablation during early development and go on to form functional adult appendages (Smith-Bolton et al., 2009). Severe 
morphological abnormalities can be induced in Xenopus during early craniofacial development and yet go on to later self-correct (Vandenberg et al., 2012; Pinet et al., 2019). This amazing ability of cells and tissues to respond to environmental changes and develop needed structures can additionally be seen in regenerating organisms. Planarians, zebrafish, Xenopus, and axolotls can regenerate entire damaged or amputated organs and limbs (Reddien and Alvarado, 2004; Roy and Gatien, 2008; Gemberling et al., 2013; Phipps et al., 2020). An extreme example can be seen in Hydra vulgaris (freshwater polyps) which are able to completely reaggregate and regenerate from dispersed cells in suspension (Gierer et al., 1972). This extraordinary ability of tissues and cells to develop correctly even when facing environmental perturbations raises one of the fundamental questions of developmental biology: how do cells communicate and coordinate in a tissue-wide manner to guide development? How does each cell know when and where to proliferate, migrate, and differentiate even in the face of perturbation?

Much of this tissue wide coordination is attributed to the morphogen signaling pathways. These morphogens, including members of the bone morphogenetic protein (BMP) pathway, Wnt pathway, Hedgehog pathway, are secreted proteins that form a concentration gradient across tissues, giving cells positional information based on the concentrations of the various morphogens. According to the morphogen concentration hypothesis, the precise concentration of each of these morphogens activates various genetic pathways that tell each cell what type of cell to differentiate into and where to differentiate (Rogers and Schier, 2011). While morphogen signaling and other canonical signaling pathways (such as Notch signaling) help explain how cells can communicate with each other across space, there is still much that is not understood about how cells precisely coordinate the spatial distribution as well as timing of cellular processes required for development. How exactly morphogen gradients are regulated is a growing question in the field, as the passive diffusion model does not adequately explain gradient formation. Recently, there has been growing evidence that in addition to the classic molecular developmental signaling pathways that cells use to coordinate development, cells use electrical signaling via ion channels to communicate (Harris, 2021; Levin, 2021). This field of research, known as developmental bioelectricity, is growing rapidly. Here, we review the evidence that ion channels are important for development in humans and other organisms, the potential mechanisms by which ion channels may be regulating development, and the next steps and barriers within the field of developmental bioelectricity.

\section{OVERVIEW OF BIOELECTRICITY IN DEVELOPMENT}

Ion channels sit within the cell membrane or organelle membranes of the cell and help regulate the levels of calcium, sodium, potassium, chloride, and other charged molecules within the cytoplasm and the other compartments in the cell. The difference in ion concentrations within the cell and in the extracellular space creates a transmembrane potential $\left(\mathrm{V}_{\text {mem }}\right)$. All cells have a resting membrane potential, but the exact value of $\mathrm{V}_{\text {mem }}$ varies by cell type. In general, differentiated cells are hyperpolarized relative to stem cells (Sundelacruz et al., 2009). Rapid changes in $\mathrm{V}_{\text {mem }}$ are essential for the functioning of excitable cells such as neurons and myocytes as these changes induce the release of neurotransmitters or contraction of muscle cells. In excitable cells these rapid changes are called action potentials. Action potentials occur when an influx of positively charged sodium depolarizes the cell, activating voltage-gated calcium channels that mediate calcium entrance. The influx of calcium activates calcium-sensitive proteins that then mediate neurotransmitter containing vesicle fusion. Eventually, potassium channels open to allow an efflux of positively charged potassium to repolarize the membrane.

While non-excitable cells do not exhibit the same rapid changes in $\mathrm{V}_{\text {mem }}$ that exitable cells do, there is growing evidence that there are $V_{\text {mem }}$ patterns and slow changes in $\mathrm{V}_{\text {mem }}$ across developing cells that influence development (Levin, 2014; Harris, 2021; Levin, 2021). Regions of relatively depolarized and hyperpolarized cells have been found within multiple different developing organisms from flies to mammals, suggesting that $\mathrm{V}_{\text {mem }}$ patterns play a conserved role in development (Figure 1). In the Drosophila larval wing disc, a stripe of cells along the anterior posterior $(\mathrm{A} / \mathrm{P})$ boundary is depolarized relative to the other cells and this $\mathrm{V}_{\text {mem }}$ pattern is important for wing development (Emmons-Bell and Hariharan, 2021). In developing mouse and chick limb buds, regions of the limb undergoing chondrogenesis shift from a relatively hyperpolarized state to a relatively depolarized state over time as chondrogenesis occurs (Atsuta et al., 2019). Disruption of this depolarized state hinders chondrogenesis (Atsuta et al., 2019). A similar patterning in $\mathrm{V}_{\text {mem }}$ can be found in developing Xenopus embryos, where dynamic regions of hyperpolarized and depolarized cells in the ectoderm change throughout development (Vandenberg et al., 2011). Clusters of hyperpolarized cells in developing Xenopus mark the developing eyes, and perturbation of this pattern disrupts eye formation (Pai et al., 2012). In developing mouse and chick limb buds, regions of the limb undergoing chondrogenesis shift from a relatively hyperpolarized state to a relatively depolarized state over time as chondrogenesis occurs (Atsuta et al., 2019). These studies suggest that $\mathrm{V}_{\text {mem }}$ may play a role in development and a wide number of studies confirm that disrupting ion channels-which collectively control the $\mathrm{V}_{\text {mem }}$-leads to developmental defects.

\section{ION CHANNEL SIGNALING IN HUMAN DEVELOPMENT}

Ion channel mediated electrical signaling is essential for the proper development of many organisms ranging from planarians to humans. In humans, a set of syndromes known as channelopathies are associated with mutations in ion channel genes. Most of these channelopathies lead to defects in the functioning of the heart or the brain, consistent with the 


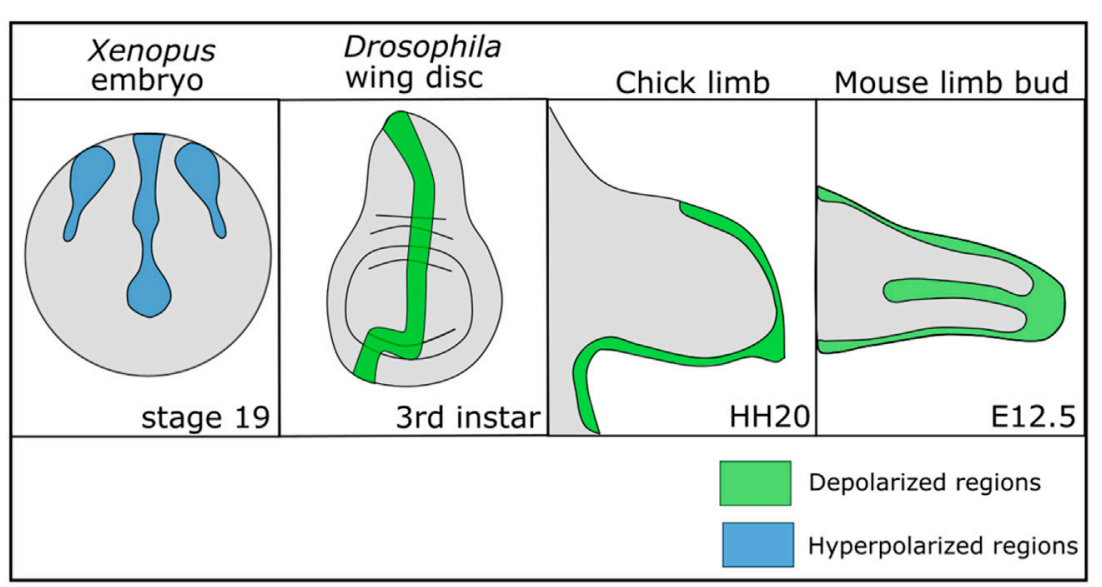

FIGURE 1 | Patterns of depolarization and hyperpolarization across various developing tissues. Developing Xenopus embryos have patterns of hyperpolarization across the ectoderm during neurulation (Vandenberg et al., 2011; Adams et al., 2016). In Drosophila melanogaster, the developing wing disc at the third instar stage has a stripe of depolarized cells along the anterior posterior boundary (Emmons-Bell and Hariharan, 2021). In developing chick and mouse limbs the mesenchyme is depolarized during chondrogenic differentiation (Atsuta et al., 2019).

known important roles of ion channels in those organs. However, many of these channelopathies are also associated with morphological defects, suggesting that ion channels play a role in the development of organs and tissues that is not limited to those tissues traditionally associated with ion channel function such as the brain. For example, Andersen-Tawil Syndrome, a channelopathy associated with a mutation in the inwardly rectifying potassium channel Kir2.1, leads to multiple morphological and craniofacial defects including short stature, low-set ears, small-lower jaw, cleft palate, clinodactyly, and syndactyly (Tawil et al., 1994; Plaster et al., 2001; Perez-Riera et al., 2020). Disruption of the homologous channel in Xenopus, Drosophila melanogaster, and mice also leads to developmental defects within those organisms, suggesting a conserved role for Kir2.1 in development (Dahal et al., 2012; Adams et al., 2016; Dahal et al., 2017; Belus et al., 2018). Timothy Syndrome, caused by gain-of-function mutations in the calcium channel $\mathrm{Ca}_{\mathrm{v}} 1.2$, is associated with multiple developmental defects including fusion of the digits of the hands or feet (syndactyly) and craniofacial defects in humans (Splawski et al., 2004; Splawski et al., 2005). Mouse and zebrafish models of Timothy Syndrome recapitulate the craniofacial defects, suggesting a conserved role for $\mathrm{Ca}_{\mathrm{v}} 1.2$ in development (Ramachandran et al., 2013). Other human syndromes that are associated with ion channel mutations and that lead to morphological defects include Temple-Baraitser Syndrome, associated with mutations in the voltage-gated potassium channel KCNH1, Birk-Barel Syndrome, associated with mutations in the two-pore domain potassium channel KCNK9, Keppen-Lubinsky Syndrome, associated with mutations in the inwardly rectifying potassium channel KCNJ6, and CLIFAHDD Syndrome, associated with mutations in the sodium leak channel NALCN (Barel et al., 2008; Chong et al., 2015; Masotti et al., 2015; Simons et al., 2015). Each of these syndromes lead to various craniofacial and digital defects (Barel et al., 2008; Chong et al., 2015; Masotti et al., 2015; Simons et al., 2015).
Outside of syndromic channelopathies there is additional evidence that disruption of ion channel function can lead to developmental defects within specific tissues and organs. For example, cystic fibrosis is caused by disruption of the epithelial chloride channel cystic fibrosis transmembrane regulator (CFTR) (Davies et al., 2007). Disruption of CFTR leads to a reduced ability of the lungs to clear bacteria and the production of viscous mucus that disrupts proper lung functioning (Davies et al., 2007). Recent evidence, however, also indicates that CFTR is required for proper development of the lungs (Larson and Cohen, 2005; Amaral et al., 2020). CFTR is expressed at very high levels during fetal lung development, and patients with cystic fibrosis present with abnormal lung development as early as 17-19 weeks gestation (Gosden and Gosden, 1984; Larson and Cohen, 2005). In CFTR knockout mice, transient expression of a normal copy of CFTR in utero rescues lethality and some of the lung and intestinal phenotypes of cystic fibrosis even when this CFTR is no longer expressed after birth, suggesting that CFTR is particularly important during development (Larson et al., 2000a). Overexpression of CFTR in both mice and primates leads to increases in proliferation and differentiation of fetal lung secretory cells, suggesting that CFTR contributes to timing of proliferation and differentiation within the lung during development (Larson et al., 2000a; Larson et al., 2000b). The identification of multiple human syndromes and developmental defects associated with ion channel disruption is just one of the many lines of evidence suggesting that ion channels are essential for development.

\section{CONSERVATION OF ION CHANNEL ROLES IN MORPHOGENESIS}

Disruption of ion channel function has been associated with developmental defects within many non-human organisms, suggesting that ion channels play a conserved role in 
morphogenesis. Dozens of ion channel mutations impacting ion channels of nearly every category have been linked to developmental defects in worms, flies, frogs, fish, and mice (Pai et al., 2012; George et al., 2019; Srivastava et al., 2021). Ion channels are important for regulating both the size and patterning of various tissues. In zebrafish, mutations in the potassium channel gene $k c n k 5 b$ lead to enlarged fins while mutations in the gap junction gene connexin43 lead to shorter fins, suggesting that ion channel signaling is important for regulating the growth and proportional size of the fins (Iovine et al., 2005; Perathoner et al., 2014; Daane et al., 2018). Mutations in many different calcium, potassium, sodium, and chloride channels in Caenorhabditis elegans have been associated with changes in body length or girth, suggesting that ion channels also regulate body size in C. elegans (Srivastava et al., 2021). In D. melanogaster a screen of wing development identified 44 ion channels important for regulating both wing size and vein patterning, suggesting bioelectrical signaling is important for the overall development of the wing (Dahal et al., 2012; George et al., 2019). Loss of Kir2.1 in mice, the inwardly rectifying potassium channel associated with Anderson-Tawil Syndrome in humans, causes craniofacial and digital defects, suggesting that Kir2.1 is important for patterning of those structures (Dahal et al., 2012; Belus et al., 2018). Injection of a dominant-negative form of the inwardly rectifying potassium channel Kir2.1 in frogs also leads to abnormal craniofacial development (Adams et al., 2016). These craniofacial defects are recapitulated by expression and activation of a lightactivated cation channel or a light activated hydrogen pump, suggesting that the role of ion channel function in craniofacial development is not limited to Kir2.1 (Adams et al., 2016). The myriad of ion channels that contribute to morphogenesis in organisms ranging from worms to humans supports the hypothesis that bioelectricity plays an important role in guiding development.

Interestingly, ion channels are important for the establishment of anterior-posterior polarity and tissue identity. For example, trunk fragments of planarians (planarians with both tail and head amputated) usually regenerate both the head and the tail at the proper ends. However, brief treatment of trunk fragments with $8-\mathrm{OH}$, a gap junction inhibitor, can lead to the regeneration of two heads, creating double-headed animals (Durant et al., 2017). This change in the body axis plan appears to be permanent, with double-headed flatworms continuing to generate two heads after subsequent amputations even when all $8-\mathrm{OH}$ has been removed (Durant et al., 2017). Treating planarian trunk fragments with ionophores to alter the resting membrane potential and depolarize the cells also results in the regeneration of double-headed organisms, suggesting that it is the depolarization of cells that regulates the development of the body axis (Durant et al., 2019). In Xenopus embryos, injection of mRNA encoding a dominant-negative form of the potassium channel Kir6.1 was sufficient to induce the formation of ectopic eyes, suggesting bioelectricity can regulate tissue identity as well (Pai et al., 2012). Together, these data strongly support the importance of bioelectrical signaling in development, including regulation of the body axis, regulation of body and body part size, and regulation of patterning.

\section{SPONTANEOUS CALCIUM OSCILLATIONS IN NON-EXCITABLE TISSUES}

Ion channels that conduct sodium, potassium, calcium, and chloride can influence the levels of cytoplasmic calcium. For example, voltage-gated calcium channels open in response to a depolarized membrane potential. Calcium release from the endoplasmic reticulum is regulated in part by ion channels that conduct other ions. Interestingly, spontaneous calcium oscillations in developing tissues exist in diverse organisms. Excitable cells such as neurons, muscle cells, or pancreatic beta cells communicate and perform their functions through rapid changes in intracellular concentrations of ions to generate action potentials. While most other cells do not propagate action potentials in the same way, many different cells and tissues propagate calcium transients and waves. Calcium waves that propagate spontaneously or in response to stimuli have been found in mesenchymal stem cells (Kawano et al., 2002), chondrocytes (Kono et al., 2006), osteoblasts (Godin et al., 2007), keratinocytes (Tsutsumi et al., 2009), endothelial cells (Uhrenholt et al., 2007; Yokota et al., 2015; Justet et al., 2019), and epithelial cells (Nathanson, 1994; Evans and Sanderson, 1999; Nihei et al., 2003). These calcium oscillations are due to rapid changes in cytosolic calcium. Calcium is stored in the endoplasmic reticulum and the mitochondria. Calcium channels and gap junctions located in the cell membrane as well as channels in the endoplasmic reticulum have been found to play a key role in the propagation of spontaneous calcium waves (Uhlén and Fritz, 2010). Calcium levels in the cytosol rise when calcium is brought across the cell membrane by gap junctions or activated-voltage gated calcium channels, or when the ER stores of calcium are released into the cytoplasm (Uhlén and Fritz, 2010). This increase in cytosolic calcium is then brought back down either by movement of the calcium through gap junctions into other cells, by being pumped back into the ER through the ATPase SERCA, being pumped out of the cell, or by being taken up by mitochondria (Uhlén and Fritz, 2010). The change in calcium levels between the cytosol, the ER, and mitochondria lead to the propagation of the calcium oscillations that are observed in cells (Uhlén and Fritz, 2010). The function of these dynamic changes in calcium is not well understood. Recently, however, these calcium waves and transients have been found within wide number of developing tissues, and disruption of the calcium oscillations disrupt morphogenesis, suggesting that calcium dynamics may help coordinate development.

Disruption of these dynamic changes in calcium in some tissues can lead to abnormal development. In D. melanogaster, the larval developing wing epithelium propagates calcium waves both in response to wounding and spontaneously in vivo (Narciso et al., 2015; Restrepo and Basler, 2016; Balaji et al., 2017; Brodskiy et al., 2019). Disruption of these calcium waves either pharmacologically or through mutations impacting ion 
channels required for these calcium waves is associated with disruption in proper Drosophila wing development (Brodskiy et al., 2019). Blue pansy butterflies also spontaneously propagate calcium waves and transients during pupal wing development and disruption of these oscillations leads to malformed scaledevelopment and eye spot formation in the wing (Ohno and Otaki, 2015). In these blue pansy butterflies, many of the calcium oscillations appear to originate from the future eye spot of the developing wing, suggesting that the calcium oscillations may instruct development of this structure in the wing (Ohno and Otaki, 2015). Calcium oscillations in developing tissues are not limited to invertebrates (Slusarski and Pelegri, 2007). Calcium oscillations have been found in budding chick feather buds and inhibition of these calcium oscillations disrupts cell migration and feather bud formation (Li et al., 2018). Calcium oscillations occur in cultured primary mouse embryonic palate cells (Isner and Bates, 2021) and they have also been imaged during early embryonic development in zebrafish (Webb and Miller, 2006), Xenopus (Wallingford et al., 2001), and mouse embryos (reviewed in Stewart and Davis, 2019). The existence of these calcium oscillations within many different organisms and tissues during development paired with the evidence that blocking them leads to developmental defects suggests that calcium oscillations are important for development.

The growing understanding of the role of spontaneous calcium oscillations and bioelectrical signaling in non-neuronal cells is reminiscent of what is known about the evolutionary development of synapses and neural connections. Research into the potential origins of neuronal synapses suggests that many synaptic proteins likely originated in non-neuronal cells before being co-opted by neurons (Ovsepian and Vesselkin, 2014; Ovsepian, 2017; Ovsepian et al., 2020). The potential use of calcium oscillations and bioelectrical signaling in the development of non-neuronal tissues may support the hypothesis that this rudimentary bioelectrical signaling may have evolved over time to help develop the fine-tuned chemical synapse in neural connections (Ovsepian and Vesselkin, 2014; Ovsepian, 2017; Ovsepian et al., 2020).

\section{ION CHANNELS IN DEVELOPMENT: POTENTIAL MECHANISMS OF ACTION}

While it is becoming increasingly evident that ion channels are essential for proper development, the mechanism by which they act is still unclear. How do cells within tissues and organs use bioelectricity during development?

Recent studies suggest that it is the differences in the $V_{\text {mem }}$ across cells that is important for development, rather than specific ion channels or ions. For example, in Xenopus laevis disruption of the homolog of Kir2.1, the channel associated with AndersonTawil Syndrome in humans, leads to craniofacial defects (Adams et al., 2016). These defects were recapitulated by optogenetic activation of a non-specific cation channel or optogenetic activation of a hydrogen pump, both expected to cause similar changes in the $\mathrm{V}_{\text {mem }}$ as Kir2.1 disruption (Adams et al., 2016). In contrast, disruption of a sodium-hydrogen exchanger that was expected to be electroneutral and cause no change in $\mathrm{V}_{\text {mem }}$ led to no disruption of craniofacial development (Adams et al., 2016). In Xenopus embryos the development of ectopic eyes can be induced by the injection of ion channel expression constructs that depolarize regions of the embryo (Pai et al., 2012). This induction of ectopic eyes is not limited to a single ion channel construct, however, and a variety of different constructs lead to the same ectopic eye formation (Pai et al., 2012). These results suggests that it is the overall $\mathrm{V}_{\text {mem }}$ which is collectively controlled by ion channels-rather than the specific identity of the channels or ions-that is important for morphological development (Adams et al., 2016).

While it is clear that $\mathrm{V}_{\text {mem }}$ is important for development, less is known about the downstream molecular mechanism by which bioelectricity regulates morphogenesis. There are several potential mechanisms by which bioelectricity may play a role in development. Calcium is required for various cellular processes that feed directly into development. What lessons can we learn from excitable cells, like neurons and pancreatic beta cells? In these cells, sodium, potassium, and chloride channels determine $\mathrm{V}_{\text {mem. }}$. Several calcium channels open or close in response to a particular Vmem. Thus, channels that do not conduct calcium contribute to intracellular calcium concentration. Could $V_{\text {mem }}$ play a central role as a regulator of calcium, which mediates proliferation, apoptosis, cell cycle control, cell polarity, cell migration, and even molecular signaling? Evidence for each of these potential mechanisms is described below.

\section{CELL DEATH PATHWAYS}

Ion channels play an important role in cell death pathways including both apoptosis and necrosis (Figure 2, and reviewed in Lang et al., 2006; Bortner and Cidlowski, 2014). Potassium leaves the cell during early apoptosis leading to a depletion of intracellular potassium (Bortner et al., 1997; Yu, 2003). This loss of potassium is important for the apoptotic pathway and inhibition of potassium efflux can prevent apoptosis (Bortner et al., 1997; Yu, 2003). Potassium is one of the most abundant ions within the cell and physiological concentrations of potassium have an inhibitory effect on caspase and nuclease activity (Hughes et al., 1997; Dallaporta et al., 1998). A number of potassium channels have been identified as playing an important role in mediating apoptosis. These include outward delayed rectifier (IK) channels, voltage-gated potassium channels, the inward rectifier Kir1.1, and multiple calcium activated potassium channels (reviewed in $\mathrm{Yu}, 2003$ ). Drops in potassium levels lead to shrinkage of the cell due to changes in osmolarity, and this shrinkage may contribute to apoptosis ( $\mathrm{Yu}, 2003)$. While lowering potassium concentration by itself is not sufficient to induce apoptosis, potassium depletion facilitates apoptosis and may be a universal part of the apoptotic pathway (Hughes et al., 1997; Dallaporta et al., 1998; Yu, 2003).

Calcium acts as a key signaling molecule in apoptosis. Calcium is stored at high concentrations in the ER and the mitochondria, and at a lower concentration in the cytosol. An imbalance of these calcium stores can lead to cell death (Figure 2A, reviewed in 


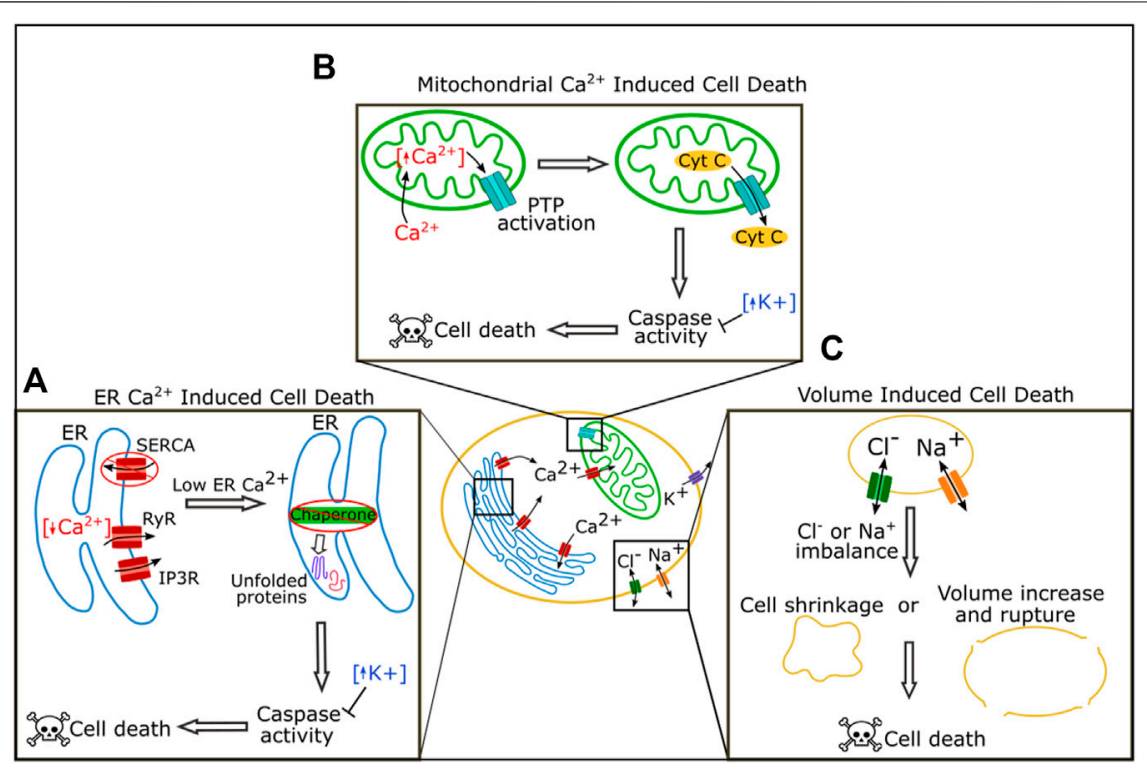

FIGURE 2 | Roles of ion channels in cell death regulation. In the ER Reduction of calcium by blockage of SERCA or increased activity of the receptors RyR and IP3R can lead to loss of chaperone function triggering the unfolded protein response pathway, caspase activation, and ultimately cell death (A). In the mitochondria, increased levels of calcium lead to activation of the permeability transition pore (PTP) which can cause leakage of cytochrome C and ultimately cause cell death (B). Chloride and sodium both regulate cell death by regulating cell volume. Extreme imbalance of chloride or sodium levels leads to cell shrinkage or volume increase and rupture, and both cause cell death (C).

Orrenius et al., 2003; Rizzuto et al., 2003; Zhivotovsky and Orrenius, 2011). Calcium was first associated with cell death when it was found that cells killed by withholding oxygen or treating with a cytotoxic drug had a dramatic rise in calcium content (Chien et al., 1977; Schanne et al., 1980). Cytosolic calcium increases during apoptosis (Martikainen et al., 1991; Kruman et al., 1998), and overactivation or disruption of calcium channels increases cell death. Disruption or overactivation of the ER calcium regulating channels inositol 1,4,5-trisphosphate (IP3) receptors (IP3Rs), ryanodine receptors (RyRs), and SERCA all increase cell death (Ruiz et al., 2010; Kiviluoto et al., 2012; Sehgal et al., 2017).

There are multiple pathways by which an imbalance in calcium levels can induce cell death (Figures 2A,B). One pathway is via the induction of prolonged ER stress (Figure 2A). The ER is an essential organelle required for protein folding and processing (Adams et al., 2019). Inside the ER, a wide variety of chaperones help process and fold new proteins, and many of these chaperones require calcium to function correctly (Adams et al., 2019). If levels of calcium in the ER drop, the ability of chaperones to efficiently fold proteins is reduced, and misfolded or unfolded proteins accumulate, a situation known as ER stress (Adams et al., 2019). ER stress initially induces the unfolded protein response (UPR) pathway (Adams et al., 2019). Long term chronic ER stress, however, leads to the expression or activation of C/EBP-homologous protein (CHOP), c-Jun N-terminal kinase (JNK), caspases, and other proapoptotic proteins, to induce apoptosis (Nakagawa et al., 2000; Hiramatsu et al., 2015).
High intracellular calcium can induce cell death through mitochondria (Figure 2B). Mitochondria take up calcium from the cytoplasm. Sharp rises in cytoplasmic calcium can overload calcium in the mitochondria which induces the opening of the permeability transition pore (PTP), a complex in the inner mitochondrial membrane (Williams et al., 2013; Bonora and Pinton, 2014). Extreme PTP activation causes swelling and rupture of the mitochondria resulting in necrosis, while milder activation of PTP can lead to leakage of cytochrome $\mathrm{C}$ and the induction of apoptosis (Bonora and Pinton, 2014).

Changes in sodium and chloride flux have also been reported during apoptosis (Figure 2C). Sodium levels increase within the cell during apoptosis, and activation of voltage-gated sodium channels (VGNCs) via the VGNC activator veratridine can induce apoptosis in neurons (Dargent et al., 1996; Koike et al., 2000; Arrebola et al., 2005). Chloride flux is important for apoptosis and blocking chloride channels can block apoptosis, perhaps because this ion regulates cell volume (Okada et al., 2004; Okada et al., 2006).

Ion channels play an important role in cell death pathways, and mediation of apoptosis is one mechanism by which bioelectricity influences development.

\section{PROLIFERATION AND CELL CYCLE REGULATION}

Ion channels play help regulate cell proliferation. The transmembrane potential of cells changes over the course of the cell cycle (Sachs et al., 1974; Wonderlin et al., 1995). It 


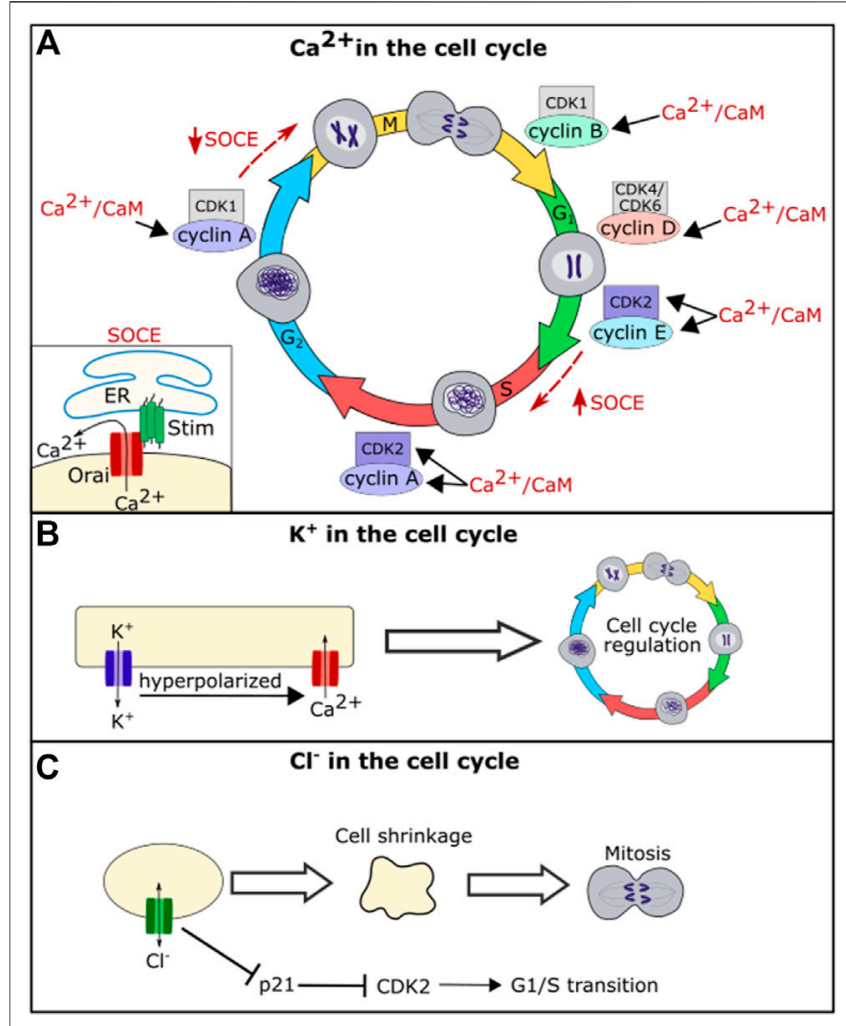

FIGURE 3 | Schematic diagram of the role of ion channel function in cell cycle regulation. $\mathrm{Ca}^{2+} / \mathrm{CaM}$ regulates levels of $\mathrm{CDK} 2$, cyclin $\mathrm{A}$, cyclin $\mathrm{B}$, cyclin D, and cyclin $E$ (A). Calcium further regulates the cell cycle through the store-operated calcium entry (SOCE) Pathway. SOCE is upregulated at the $\mathrm{G} 1 / \mathrm{S}$ phase transition and downregulated at the G2/M phase transition (A). Potassium flux hyperpolarizes the cell, which helps drive calcium into the cell regulating calcium influence on the cell cycle (B). Chloride flux is required for the cell shrinkage that is necessary for mitosis and also regulates levels of p21 (C).

was observed as early as the 1970s that depolarization could induce mitosis of neuronal precursors (Stillwell et al., 1973; Cone and Cone, 1976). It is now known that calcium, potassium, sodium, and chloride all play roles in regulating the cell cycle (Blackiston et al., 2009).

Calcium plays an essential role in regulating the cell cycle at nearly every transition step (Humeau et al., 2018) (Figure 3). The cell cycle is controlled by cyclin-dependent protein kinases (CDKs) that activate upon binding to a cyclin. Expression of each of the cyclins regulates the CDK complexes and guides entry into the next phase of the cell cycle. Calcium feeds into the cell cycle primarily by regulating calmodulin $(\mathrm{CaM})$ and calcineurin (CaN) (Humeau et al., 2018). CaM is a protein that is activated upon binding of calcium. $\mathrm{Ca}^{2+} / \mathrm{CaM}$ can directly regulate $\mathrm{CDKs}$ and cyclins or act through activation of calcineurin, a phosphatase that activates upon $\mathrm{Ca}^{2+} / \mathrm{CaM}$ binding (Kahl and Means, 2003). Together $\mathrm{Ca}^{2+} / \mathrm{CaM}$ and $\mathrm{Ca}^{2+} / \mathrm{CaM}$ activatedcalcineurin regulate many of the CDKs and cyclins (Kahl and Means, 2003). For example, calcium acts through CaM or $\mathrm{CaN}$ activation to regulate the levels CDK1, CDK2, cyclin A, cyclin D, and cyclin $\mathrm{E}$ within various cell types (Colomer et al., 1994;
Tomono et al., 1998; Kahl and Means, 2004; Humeau et al., 2018) (Figure 3).

In addition to acting through $\mathrm{CaM}$ and its downstream pathways, calcium oscillations are important for regulating cell cycle phase transitions. Calcium oscillations have been found to be important for the $G_{1} / S$ phase transition. The store-operated calcium entry (SOCE) pathway, a pathway in which the calcium channels Stim and Orai work to bring calcium into the cell upon ER calcium depletion, was found to be upregulated during $G_{1} / S$ phase transition and downregulated prior to the $\mathrm{G} 2 / \mathrm{M}$ phase transition (Chen et al., 2016) (Figure 3). Blocking SOCE can lead to G1 arrest (Short et al., 1993; Chen et al., 2016). Treating cells with calcium blockers can also lead to inhibition of the metaphase-anaphase transition, suggesting that calcium helps regulate the mitotic spindle checkpoint in addition to the $G_{1} / S$ phase transition (Xu et al., 2003). Together these data suggest that calcium is an important second messenger for regulating both cell death and cell life pathways.

There is a large body of evidence that indicates that potassium also plays an important role in cell-cycle regulation (Urrego et al., 2014). Treating cells with potassium channel blockers can block proliferation (DeCoursey et al., 1984; Amigorena et al., 1990; Lee et al., 1993), and this is partially due to potassium's role in calcium movement. The potassium gradient hyperpolarizes the cell membrane, driving calcium entry into the cell and thus potassium can regulate the cell cycle via the calcium mediated pathways described above (Urrego et al., 2014). However, the role of potassium channels in hyperpolarizing the cell membrane is not the only mechanism by which they influence the cell cycle. Multiple potassium channels including $\mathrm{K}_{\mathrm{V}} 1.3, \mathrm{~K}_{\mathrm{V}} 3.1$, and $\mathrm{K}_{\mathrm{V}} 10.1$ impact the cell cycle even when they are modified to prevent ion permeation, suggesting that they may interact with cell signaling via a mechanism that is independent of potassium conduction (Downie et al., 2008; Millership et al., 2011; Cidad et al., 2012; Urrego et al., 2014).

While chloride appears to play a less important role in the cell cycle than calcium and potassium, the chloride channel $\mathrm{ClC} 3$ plays a role in cell cycle regulation in nasopharyngeal carcinoma cells and in glial cells, with disruption of CIC3 inhibiting cell proliferation (Habela et al., 2008; Xu et al., 2010). ClC3 regulates cell volume, and chloride efflux is necessary to cause the reduction in volume seen in mitotic cells (Habela et al., 2009). A reduction in cell volume via efflux of salt and water is important for mitosis, and cells that are forced to maintain a larger volume take longer to divide (Habela and Sontheimer, 2007). When chloride flux is blocked, cells cannot reduce their volume prior to mitosis, and this leads to a delay in cell division. Intracellular chloride levels have also been shown to directly regulate the cell cycle by regulating the expression level of p21. Loss of chloride leads to an upregulation of p21 which in turn leads to a downregulation of CDK2 and cell cycle arrest at the $G_{1} / S$ cell cycle checkpoint (Miyazaki et al., 2008; Shiozaki et al., 2011). Changes in proliferation because of disruption of ion channel function in individual cells would impact the size of a whole tissue.

The role of ion channels in proliferation as well as cell death pathways is one of the primary reasons that ion channel 
mutations are common in cancer cells. The role of ion channels in cancer has been reviewed extensively (Lang and Stournaras, 2014; Prevarskaya et al., 2018). The variety of ion channels linked to cancer suggest that ion channels play an important role in regulating the cell cycle.

\section{CELL POLARITY AND MIGRATION}

Ions are important for both the establishment of cell polarity and the progression of cell migration (Campetelli et al., 2012). In human bone osteosarcoma U2OS cells, it has been observed that many calcium channels, including those that regulate the ER stores of calcium, tend to concentrate at the rear end of polarized cells (Huang et al., 2015). Disruption of a variety of calcium channels using drugs that targeted transient receptor potential channels (TRPC), calcium release activated channels (CRAC), or store-operated calcium entry (SOCE) channels, all led to a decrease in cell polarization (Huang et al., 2015). Disruption of STIM via knockdown or expression of a dominant-negative form of STIM, similarly reduced cell polarization (Huang et al., 2015). While the mechanism by which calcium channels regulate cell polarity is unclear, at the immune synapse calcium organizes actin filament formation (Hartzell et al., 2016). Actin plays an essential role in planar cell polarity, and it is possible that calcium impacts cell polarity by regulating actin dynamics.

The establishment of cell polarity is essential for the migration of cells. Calcium plays roles in cell migration in vivo as well as in cell culture. For example, blocking spontaneous calcium waves in the developing chick feather bud disrupts normal cell migration leading to malformed feather buds (Li et al., 2018). Calcium is similarly important for the migration of zebrafish primordial germ cells (PGCs) (Blaser et al., 2006). In these PGCs it was found that calcium levels increased at the front of migrating cells and this increase was necessary for proper migration (Blaser et al., 2006). Blaser et al. hypothesize that this increase in calcium may activate actomyosin contraction, directing cell migration (Blaser et al., 2006). Cell migration is important for morphogenesis of several structures. If individual cells cannot migrate properly due to inhibition or loss of ion channel function, cells will not be in the right place at the right time to send or receive developmental signals and the tissue would not develop normally. In addition, lack of effective migration could prevent the correct number of cells from reaching their proper location in a tissue. Therefore, disruption of ion channels could impact the development of a structure by hindering cellular migration.

Other ions contribute to establishment of cell polarity. Inhibition of $\mathrm{Na}, \mathrm{K}-\mathrm{ATP}$ ase or treatment with a sodium ionophore in epithelial cells leads to a loss of cell polarity, suggesting that regulation of sodium is important for establishment of cell polarity (Rajasekaran et al., 2001). Overexpression of RhoA GTPase rescues this loss of cell polarity (Rajasekaran et al., 2001). Rho organizes actin and tight junctions in polarized epithelia (Nusrat et al., 1995), so this suggests that sodium is important for this Rho-dependent cell polarization pathway.

\section{REGULATION OF CANONICAL DEVELOPMENTAL SIGNALING PATHWAYS}

While ion channels and ions regulate many essential cellular processes long known to be important for development, there is a more recent hypothesis that ion channels may directly regulate the morphogen signaling pathways to coordinate development. Within multiple organisms, loss of ion channel function is associated with disruptions in the BMP signaling pathway, the Notch signaling pathway, the Wnt signaling pathway, and the Hedgehog signaling pathway.

\section{Bone Morphogenetic Protein Pathway}

BMPs are signaling proteins that are essential for the development of organs and tissues, regulating proliferation, apoptosis, and differentiation. Disruption of various ion channels leads to defects in BMP signaling, suggesting that bioelectrical signaling may help regulate this pathway. In mouse bone marrow mesenchymal stem cells (BMSCs), a disruption of BMP signaling and differentiation was found upon knockout of the calcium channel Orail (Lee et al., 2016). This disruption of BMP signaling could be rescued by expression of a constitutively active BMP receptor (Lee et al., 2016). Orail is a CRAC that helps regulate ER calcium, so loss of BMP signaling upon Orail knockout suggests that ER calcium may help regulate BMP signaling in mouse BMSCs. Another channel involved in ER calcium regulation, sarcoendoplasmic reticulum calcium transport ATPase (SERCA) plays a role in the regulation of BMP signaling. In the D. melanogaster air sac primordium (ASP), downregulation of SERCA leads to a decrease in BMP/Dpp signal transduction (Huang et al., 2019). Similar impacts on BMP/Dpp signal transduction were found upon knockdown of the voltage-gated calcium channel genes straightjacket (stj) and cacophony (cac) (Huang et al., 2019). Interestingly this disruption of BMP/Dpp signal transduction in the ASP was also found upon knockdown of the calcium binding proteins Syt4 or synaptobrevin (Syb) (Huang et al., 2019). Syt4 and Syb are both involved in vesicle trafficking, suggesting that proper BMP/Dpp signaling in this system may require vesicle trafficking mediated by calcium (Huang et al., 2019).

Potassium channels also play a role in BMP/Dpp signaling. Kir2.1 is an inwardly rectifying potassium channel that when disrupted in humans is associated with morphological differences as part of Andersen-Tawil Syndrome. Kir2.1 function is associated with proper BMP signaling in multiple organisms. In mice, Kir2.1 knockout leads to abnormal limb development, craniofacial defects, and a significant reduction in Smad 1/5/8 phosphorylation indicating that Kir2.1 is required for BMP pathway functioning in mammals (Belus et al., 2018). Similar craniofacial defects occur in developing frogs upon loss of Kir2.1 function (Adams et al., 2016). In the Drosophila wing disc, loss of function of Irk2, the Drosophila ortholog of Kir2.1, reduces downstream phosphorylation of Mad and BMP/Dpp target gene expression (Dahal et al., 2012). The similar developmental disruptions that occur in flies, frogs, and mice upon Kir2.1/Irk2 disruption, suggest that this potassium channel plays a conserved role in development. 


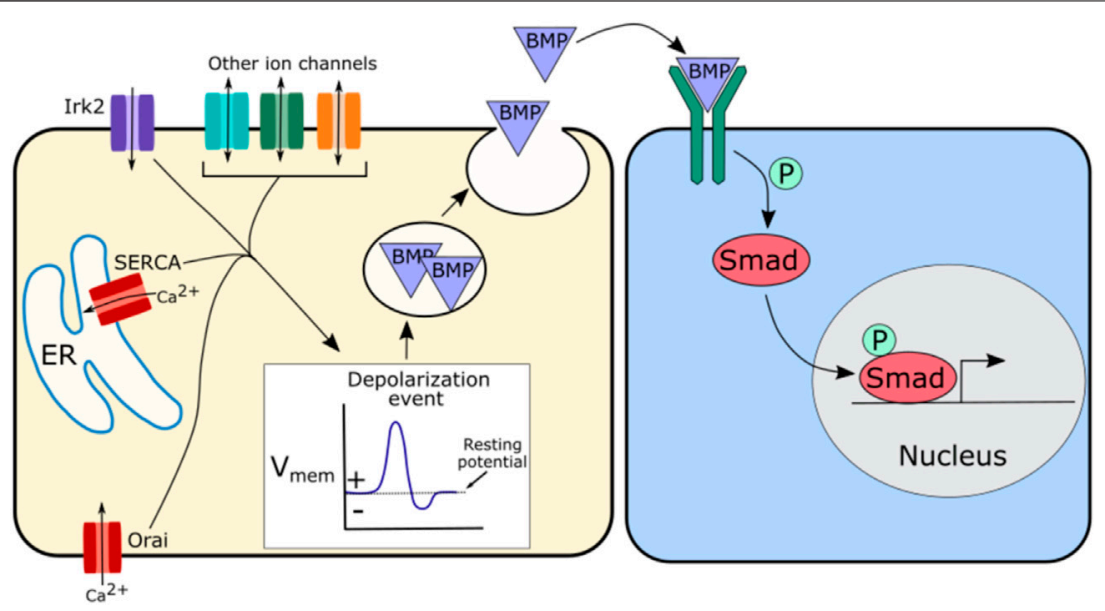

FIGURE 4 | Schematic of potential mechanism by which ion channels may regulate BMP signaling. Irk2, SERCA, and Orai have all been implicated in BMP signaling, but other channels are likely involved as well. A suggested hypothesis is that these ion channels regulate depolarization events that in turn regulate the release of BMP containing vesicles. This regulated release of BMP further regulates BMP pathway activity downstream by modulating the availability of morphogen levels.

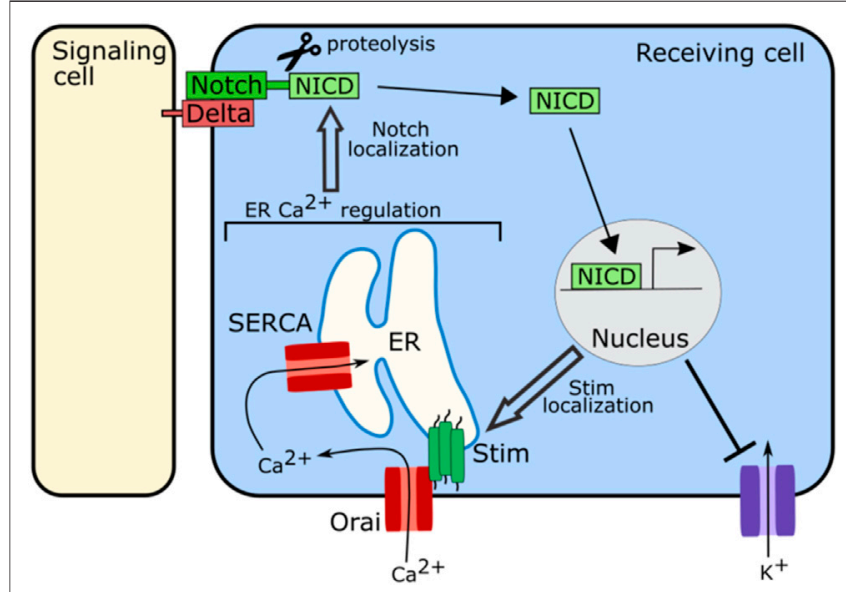

FIGURE 5 | Schematic of role of ion channels in Notch signaling. The ion channels involved in regulating calcium levels in the ER including SERCA, Stim, and Orai, are required for proper localization of Notch at the cell membrane to participate in signaling. Notch signaling in turn regulates the localization and clustering of Stim. Notch signaling also attenuates the activity of potassium channels.

In Drosophila loss of Irk2 function disrupts BMP/Dpp secretion dynamics, likely leading to the disruption of $\mathrm{BMP} /$ Dpp signaling and defects in wing morphogenesis (Dahal et al., 2012; Dahal et al., 2017). Irk2 disruption also abolishes spontaneous calcium oscillations in the wing, so this impact of Irk2 on BMP/Dpp secretion may be mediated through its impact on calcium (Dahal et al., 2012; Dahal et al., 2017). One potential hypothesis is that Irk2 along with calcium channels or other ion channels regulate depolarization events, which in turn regulate the fusion of BMP/Dpp containing vesicles to the cell membrane (Figure 4). This would explain a potential mechanism by which $\mathrm{BMP} / \mathrm{Dpp}$ secretion could be regulated, impacting propagation of the downstream BMP signaling pathway. Depolarization of the developing Drosophila wing evokes BMP/Dpp release, supporting this model (Dahal et al., 2017).

\section{Notch Pathway}

Notch signaling is another canonical developmental signaling pathway that is impacted by the disruption of ion channels. Notch signaling is a conserved signaling pathway required for the development of many tissues and organs (Kopan and Ilagan, 2009). The ligands in the Notch pathway are transmembrane proteins rather than secreted ones and thus Notch signaling acts as a short range signal (Kopan and Ilagan, 2009). Notch signaling regulates cell division, cell death, and cell differentiation (Kopan and Ilagan, 2009).

Regulation of ER stores of calcium are important for proper functioning of the Notch signaling pathway (Figure 5). In Drosophila, SERCA, a channel that pumps calcium into the ER, is particularly important for Notch signaling. Disrupting SERCA function in Drosophila S2 cells, in the Drosophila eye, or in the Drosophila larval wing disc, leads to developmental defects consistent with a loss of Notch signaling as well as an accumulation of notch and delta receptors in intracellular vesicular structures away from the cell surface (Periz and Fortini, 1999; Suisse and Treisman, 2019). This accumulation of notch away from the cell surface is also seen in the Drosophila wing disc when Orai is knocked down (Suisse and Treisman, 2019). Orai and SERCA both act to regulate ER calcium levels, suggesting that ER calcium is important for the trafficking of notch or delta (Figure 5). Loss of SERCA functioning in human leukemia cells, also leads to intracellular accumulation of Notch with the Notch1 receptor failing to fully mature, suggesting that this role of ER calcium in Notch signaling may be conserved (Roti et al., 2013). The Notch receptor contains calcium binding EGFlike repeats, and it is possible that when calcium levels in the ER drop, the notch receptor is no longer able to fold correctly leading 


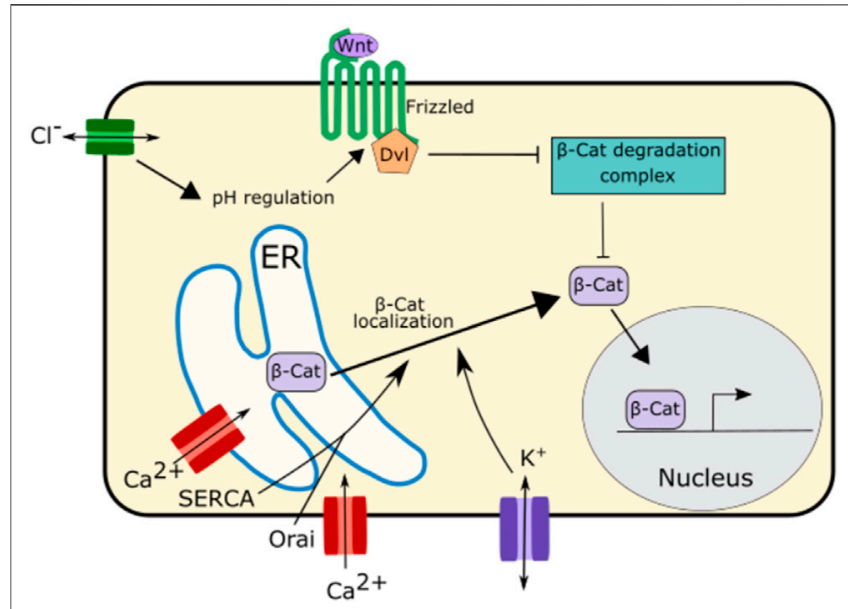

FIGURE 6 | Schematic of mechanisms by which ion channels regulate Wnt signaling. The ER calcium regulating channels SERCA and Orai as well as potassium channels regulate the localization and trafficking of $\beta$-Catenin from the ER to the cytoplasm. This enables $\beta$-Catenin to participate in Wnt signaling.

to its accumulation within the ER or a failure to traffic correctly to the cell surface (Rand et al., 1997).

Notch signaling also regulates bioelectricity (Figure 5). In human embryonic kidney 293 (HEK293) cells and in myocytes upregulation of Notch signaling has been associated with an increase in cytosolic calcium and decreases in potassium flux (Khandekar et al., 2016; Song et al., 2020). In the HEK293 cells Notch signaling attenuates the activity of voltage-gated potassium channels while also inducing clustering of Stim channels, leading to an influx of calcium into the cytoplasm from the ER (Song et al., 2020). These results suggest that Notch signaling may both regulate and be regulated by ion channel function.

\section{Wnt Pathway}

Wnt Signaling, another important developmental signaling pathway is also regulated by ion channel function. In the Drosophila wing disc disruption of SERCA, an ER calcium channel, causes E-Cadherin to be retained in the ER (Suisse and Treisman, 2019). This causes $\beta$-catenin/Arm, which binds to E-Cadherin, to be sequestered in the ER and unable to participate in signaling, leading to downregulation of Wnt signaling (Suisse and Treisman, 2019) (Figure 6). This downregulation of Wnt signaling was also found upon disruption of the ER calcium regulating channel Orai, suggesting that ER calcium plays an important role in Wnt signaling (Suisse and Treisman, 2019) (Figure 6).

While there is evidence that calcium is important for Wnt signaling propagation, potassium and chloride both appear to play even more important roles in this pathway (Rapetti-Mauss et al., 2020) (Figure 6). Potassium regulates the localization of $\beta$ catenin impacting Wnt signaling. Inhibition of the potassium channel KCNQ1 downregulates Wnt/ $\beta$-catenin signaling. This is due to the role of KCNQ1 in regulating the membrane potential. Overactivation of KCNQ1 hyperpolarizes cell membrane while inhibition of KCNQ1 depolarizes the cell membrane (RapettiMauss et al., 2017; Rapetti-Mauss et al., 2020). Inhibition of KCNQ1 and the subsequent depolarization of the membrane inhibits $\beta$-catenin from localizing to the cell membrane attenuating $\mathrm{Wnt} / \beta$-catenin signaling (Rapetti-Mauss et al., 2017; Rapetti-Mauss et al., 2020).

Chloride signaling, too, has been associated with regulation of Wnt $/ \beta$-catenin signaling. Disruption of CTFR, the chloride channel associated with cystic fibrosis, leads to an increase in intracellular $\mathrm{pH}$ (Strubberg et al., 2018). This change in $\mathrm{pH}$ enhances the interaction between the Wnt signaling receptors Disheveled and Frizzled leading to an increase in Wnt signaling (Strubberg et al., 2018; Rapetti-Mauss et al., 2020). This increase in Wnt signaling upon CTFR disruption may be one of reasons why cystic fibrosis is associated with abnormal lung development and increased risk of gastrointestinal cancer (Neglia et al., 1995; Larson and Cohen, 2005).

\section{Hedgehog Pathway}

The hedgehog signaling pathway family members, including sonic hedgehog (Shh), desert hedgehog (Dhh), and Indian hedgehog (Ihh) all play an essential role in embryonic patterning and development (Choy and Cheng, 2012). In the hedgehog pathway, the ligands act as secreted morphogens facilitating longer range signaling (Choy and Cheng, 2012). While evidence suggests that calcium can regulate BMP and Notch signaling, in contrast hedgehog signaling appears to primarily act upstream of calcium, regulating calcium oscillations. Recent studies suggest that calcium may play an important role in the execution of the hedgehog signaling pathway. In zebrafish, disruption of intracellular calcium release from the ER via RyRs resulted in abnormal neural tube patterning which was attributed to a loss of Shh-dependent gene expression (Klatt Shaw et al., 2018). RyR function was found to be specifically important for the Shh ligand receiving cells, indicating a role for calcium in Shh signal transduction (Klatt Shaw et al., 2018). Multiple other studies have also implicated spikes of calcium in the execution of Shh induced signaling in Xenopus, mouse, and rat embryos and cell lines (Osawa et al., 2006; Heo et al., 2007; Belgacem and Borodinsky, 2011). While the exact mechanism by which Shh induced calcium oscillations modulate gene expression is unclear, it has been suggested that Shhmediated induction of calcium activates ERK signaling which in turn changes gene expression (Osawa et al., 2006). Shh was also found to mediate calcium oscillations in chick feather buds ( $\mathrm{Li}$ et al., 2018). In the chick feather bud it was found that Shh could induce expression of the calcium channels Connexin-43 and Stim1 to induce calcium oscillations which were important for the migration of the cells in the bud (Li et al., 2018).

In the developing Drosophila wing (wing disc), hedgehog signaling and ion channel control of $\mathrm{V}_{\text {mem }}$ mutually reinforce each other (Emmons-Bell and Hariharan, 2021) (Figure 7). A Vmem reporting dye shows a stripe of depolarized cells can be found near the anterior/posterior $(\mathrm{A} / \mathrm{P})$ boundary, with the depolarization becoming more restricted to the anterior side of the boundary over time (Emmons-Bell and Hariharan, 2021). Disrupting degenerin epithelial $\mathrm{Na}^{+}$channels (DEG/ENaC) 


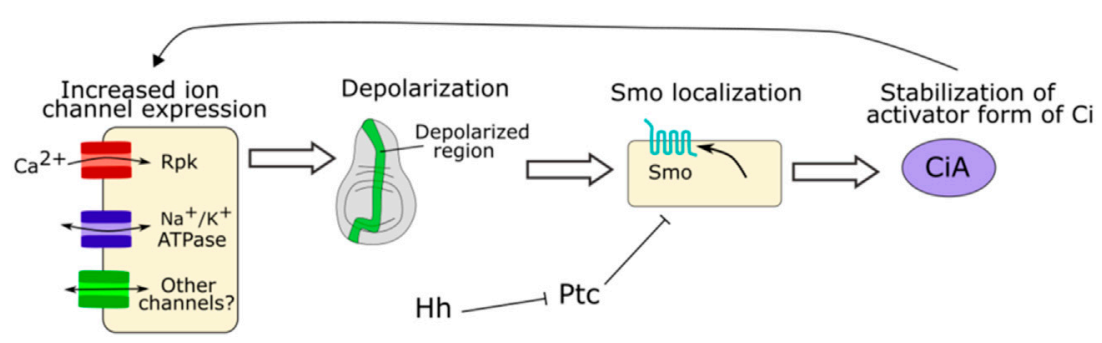

FIGURE 7 | Schematic of role of ion channel function in Hh signaling. In the Drosophila wing increased expression of Rpk and $\mathrm{Na}^{+} / \mathrm{K}^{+}$ATPase and other ion channels generates a depolarized region in the developing wing disc. This depolarization is necessary for proper Smo localization and downstream stabilization of Ci. In turn, Hh signaling regulates levels of Rpk and $\mathrm{Na}^{+} / \mathrm{K}^{+}$ATPase (Emmons-Bell and Hariharan, 2021).

prevents depolarization of that stripe of cells (Emmons-Bell and Hariharan, 2021). Upon both an increase or decrease in hedgehog signaling via activation of a temperature sensitive hedgehog allele or a constitutively active Cubitus interruptus $(\mathrm{Ci})$ allele, the expression levels of the DEG/ENaC channel Rpk and the $\mathrm{Na}^{+}$/ $\mathrm{K}^{+}$ATPase subunit ATPa were found to change (Emmons-Bell and Hariharan, 2021). These expression levels of Rpk and ATPa correspond with a change in $\mathrm{V}_{\text {mem }}$, suggesting that hedgehog signaling regulates the Vmem pattern of cells within a tissue via regulation of ion channel expression (Emmons-Bell and Hariharan, 2021). Conversely, reducing expression of Rpk or ATPa using wing-specific RNAi reduces Hh signaling (EmmonsBell and Hariharan, 2021). Direct modulation of $\mathrm{V}_{\text {mem }}$ via optogenetics regulates smoothened membrane localization, suggesting that bioelectricity regulates $\mathrm{Hh}$ signaling while also being regulated by it (Emmons-Bell and Hariharan, 2021). This suggests that $\mathrm{Hh}$ signaling and $\mathrm{V}_{\text {mem }}$ mutually reinforce each other (Figure 7).

Taken together, these studies suggest that all of the major canonical signaling pathways can be regulated by bioelectricity. Notch and Hh signaling regulate ion channel signaling while also being regulated by changes in bioelectricity. BMP and Wnt signaling both lie downstream of ion channel function and the activity of these pathways can be modulated by changes in bioelectricity.

\section{DIRECT REGULATION OF TRANSCRIPTION}

Salvador Mafe, Michael Levin, and Javier Cervera have proposed that membrane potential could regulate transcription directly (Cervera et al., 2020; Levin, 2021). Thus, bioelectric signals could coordinate cellular outcomes between several cells within a developing tissue. In this model, bioelectric fields would control development on a tissue wide scale.

\section{PUTTING IT ALL TOGETHER: IMPLICATIONS OF BIOELECTRICAL SIGNALING}

It is becoming increasingly evident that ion channel function and the $\mathrm{V}_{\text {mem }}$ pattern in tissues is essential for development. Because ion channels play roles in nearly every essential developmental process including cell death, proliferation, cell polarity, migration, and regulation of the canonical developmental signaling pathways, this raises the exciting possibility that cells within tissues may use bioelectrical signaling as a high-level mechanism to coordinate the complex process of development of a tissue. While we described mechanisms on an individual cell level, in multicellular organisms, cells are working within a tissue. Thus, the contribution of ion channels to proliferation, apoptosis, cell migration, and signaling would impact the morphogenesis of a whole tissue or structure. For example, if the ion channels that impact proliferation and migration are inhibited during palatogenesis, the correct number of cells would not migrate to the palate shelves and would not proliferate adequately for palate shelves to reach one another and fuse at the midline, which would result in a cleft palate.

Calcium appears to be the major player in bioelectrical signaling. In each of the cellular processes which ion channels help regulate, calcium channels play the largest role of all of the ion channel types: calcium is the primary ion that acts in ion channel mediated regulation of cell death, working in both the ER related and mitochondria related cell death pathways, calcium acts at nearly every stage in the cell cycle to regulate proliferation, calcium channels are required for the establishment of cell polarity and for cell migration, and calcium plays a role in BMP, Notch, Wnt, and Hh signaling. ER regulating calcium channels are specifically required for many of these processes with SERCA, Stim, or Orai having been identified as necessary for nearly all of these cellular processes (Figure 2-Figure 6). Remarkably, these ER-calcium regulating channels are also necessary for the propagation of the calcium oscillations that occur spontaneously in developing tissues (Narciso et al., 2015; Ohno and Otaki, 2015; Restrepo and Basler, 2016; Balaji et al., 2017; Li et al., 2018), providing a potential link between calcium oscillations and these calcium-regulated cellular processes. The near universal existence of calcium oscillations in developing tissues paired with the known roles of calcium in multiple cellular processes and pathways raises intriguing possibilities for the role of calcium in guiding development. Calcium oscillations provide a mechanism by which cells could communicate in detailed ways. Oscillations contain many encoded variables-such as frequency, amplitude, and rate of change-that could each potentially carry information, allowing cells to fine-tune communication through 
subtle changes in oscillatory properties. Could it be that a variety of ion channels contribute to development by converging on regulation of intracellular calcium?

Cellular concentrations of one ion can influence concentrations of other ions. If the activity of one type of ion channel is impaired, concentrations the ion it conducts are altered, but concentrations of other ions can be changed as well. For example, membrane potential impacts cytoplasmic calcium levels. This is due to the high number of voltagegated calcium channels that are able to respond to changes in $\mathrm{V}_{\text {mem }}$ by opening or closing and allowing or stopping calcium flux (Catterall, 2011). Many other channel types-including potassium, sodium, and chloride channels-are calcium sensitive and open upon calcium binding and lead to changes in $\mathrm{V}_{\text {mem }}$. Calcium-activated potassium channels in particular have been associated with calcium induced changes in $V_{\text {mem }}$ (Lazzari-Dean et al., 2019). This feedback between calcium levels and $V_{\text {mem }}$ allows both properties to mutually regulate each other.

The known roles of calcium oscillations and $\mathrm{V}_{\text {mem }}$ in development suggest a model in which these factors can be used for communication. A potential model can be imagined in which cells within growing tissues have varying $V_{\text {mem }}$ values depending on their location within the tissue and the propagation of calcium oscillations. Because mechanical forces can induce changes in $\mathrm{V}_{\text {mem }}$ and calcium oscillations it is possible that the individual forces on each cell-which depend on the cell's placement within a tissue-may help regulate this bioelectrical signaling. In turn, these bioelectrical signals could regulate the proliferation, death, cell polarity, and migration of each cell while also regulating the canonical developmental signaling pathways, ultimately guiding each cell to differentiate at the proper time and place to form the adult organism. Because bioelectrical signals such as calcium oscillations can encode multiple different variables, information could be fine-tuned to each cell. Whether a cell decides to divide, proliferate, die, or differentiate could depend not only on an overall level of a particular ion but on the combination of $\mathrm{V}_{\text {mem }}$ and calcium oscillation frequency or amplitude. Cells within tissues are interconnected via a vast network of gap junctions, so the bioelectrical state of each cell could in turn regulate the bioelectrical states of cells nearby. This model would suggest a mechanism by which cells are able to communicate rapidly and dynamically in response to perturbations such as damage during development.

\section{NEXT STEPS IN THE FIELD OF BIOELECTRICITY}

\section{Remaining Questions}

Ion channels have emerged as important regulators of cell death, cell cycle regulation, cell polarity, migration, and canonical developmental signaling pathways. While the field of developmental bioelectricity is rapidly growing, there are still many questions to be answered.

It has only recently been discovered that ion channels play a role in well-established developmental signaling pathways such as
BMP, Wnt, and Notch. How do the important molecular signaling pathways and ion channel signaling intersect? Ion channels clearly impinge upon BMP, hedgehog, notch, and wnt signaling pathways, but it is not well understood whether these effects are due to direct regulation of these pathways or due to downstream effects on cell cycle, cell death, or cell migration. While some research suggests that the role of ion channels in signaling is via a direct mechanism such as regulation of the secretion or trafficking of components of the BMP and notch signaling pathways (Dahal et al., 2017; Suisse and Treisman, 2019), more studies need to be done specifically investigating these potential mechanisms and whether these roles are conserved in development.

Another question in the field is whether the role of ion channel signaling in development is mediated primarily through impacting the transmembrane potential or through impacts on the spontaneous calcium oscillations that occur in developing organisms. As previously mentioned, both calcium oscillations and transmembrane potential are intrinsically related and influence each other. However, more work needs to be done to understand whether each property influences different aspects of development or whether both properties work within the same pathway. Much of the recent work in the field of developmental bioelectricity has focused on the patterns of $V_{\text {mem }}$ across developing tissues and how these patterns might instruct development. However, while it is clear that transmembrane potential patterns across tissues are an important regulator of multiple cellular processes, there is evidence that the more slight but rapid changes in $\mathrm{V}_{\text {mem }}$ that occur via the propagation of calcium oscillations also play an important role in developing tissues. The discovery that many tissues spontaneously propagate calcium transients and waves, raises the possibility that cells could use ionic signaling to communicate across greater distances like neurons. There is evidence that ion channels may impact secretion dynamics of cell signaling pathways and that developing tissues propagate calcium waves. Are these calcium waves regulating morphogen secretion similar to the way action potentials regulate neurotransmitter release in neurons? Recent work in the Drosophila air sac primordium suggests that such a mechanism may be at work in cell types not traditionally thought of as excitable (Huang et al., 2019). In most tissue types, cells are connected via a vast network of gap junctions, enabling such changes in calcium to be used to communicate across tissues. More work needs to be done to investigate whether similar regulation of morphogens via calcium oscillations occurs in other cell and tissue types. With new tools in optogenetics and calcium sensing now readily available and improving, this research is now possible.

Another unanswered question in the field is how the transmembrane potential and calcium oscillations are regulated and coordinated on a tissue wide scale. If cells are using the transmembrane potential and calcium waves to communicate, then they must still be able to sense their position within a tissue to adopt the correct $\mathrm{V}_{\text {mem }}$. What upstream information allows cells to properly set their transmembrane potential and propagate calcium oscillations? Because many ion channels are sensitive to mechanical stresses, one hypothesis is that mechanical forces between cells within a tissue may guide ionic signaling. Mechanical forces play an important role in development, and 
mechanosensitive ion channels have been associated with cell processes such as development of cell polarity and migration (Mammoto and Ingber, 2010; Huang et al., 2015; Canales Coutino and Mayor, 2021). In fact, mechanical stressors have been found to induce calcium waves in many cell types and tissues (Godin et al., 2007; Tsutsumi et al., 2009; Narciso et al., 2015; Restrepo and Basler, 2016). Another possibility is that some of the well-established developmental signaling pathways may also shape calcium oscillations. The hedgehog signaling pathway is upstream of calcium waves, suggesting an alternative mechanism by which ion gradients may be regulated (Osawa et al., 2006; Belgacem and Borodinsky, 2011; Klatt Shaw et al., 2018; Li et al., 2018). More work needs to be done, however, to fully understand how calcium oscillations and $\mathrm{V}_{\text {mem }}$ patterns are established and regulated as tissues grow.

While there is a rising understanding of the role of ion channel function in each of the key developmental cellular processes of proliferation, cell death, migration, and molecular cell signaling, less is understood about how bioelectrical signaling may regulate these processes all together and how the bioelectrical patterns and each of these processes interconnect across a tissue. For example, oscillations in calcium play a role in progression of the cell cycle, induction of cell death, and activation of cell migration. How does the cell distinguish between these signals? When cytosolic calcium rises how does the cell know whether to divide, die, send a molecular signal, or migrate? One possibility is that the cell responds to narrow ranges of $\mathrm{V}_{\text {mem }}$ changes and calcium levels, with information potentially encoded within the frequency or amplitude of calcium oscillations. The resting membrane potential of a given cell in a tissue along with the active genes in each cell type, could dictate how easily calcium influx is induced and to what degree $\mathrm{V}_{\text {mem }}$ changes in response, which in turn could regulate whether the cell responds by dividing, dying, migrating, or propagating a developmental signaling pathway. For example, a specific cell that is already in a relatively depolarized region within a tissue would need less calcium influx to reach a specific calcium threshold than a cell in a relatively hyperpolarized region. However, calcium influx into the cell in the hyperpolarized region to reach the same final calcium threshold would result in a final amplitude with larger magnitude. Could these two different variables-time to threshold calcium level or final amplitude of calcium oscillation-encode different information? More work needs to be done on mapping the tissue wide patterns of bioelectrical signaling, the regions of calcium oscillation propagation, and developmental processes to broaden our understanding of how bioelectrical signaling may coordinate development at a tissue wide level.

\section{Potential Barriers}

While much progress has been made in the field of developmental bioelectricity, there are still barriers that must be addressed. One difficulty is the many overlapping roles of ions, particularly calcium, in cell processes essential to development. Calcium acts as a messenger in a variety of developmental processes: regulating cell death, the cell cycle, cell polarity, migration and well-established developmental signaling pathways. Because many of these pathways impinge upon on the others attributing changes in developmental outcomes to specific pathways is difficult. More work needs to be done within controlled contexts such as cell culture systems to understand how calcium specifically impacts recognized signaling pathways apart from its impact on cell death and the cell cycle.

Another difficulty in elucidating the role of ion channels in development is that there is a limited ability to control a single ionic pathway without impacting others. Levels of calcium, potassium, sodium, and chloride all intersect with each other, which the levels of each ion impacting the levels of the others, making it difficult to distinguish roles of specific ion channels and ions. Much of the research in the field of developmental biology has focused on disruption or manipulation of specific individual genes to elucidate the roles of individual proteins. In the field of bioelectricity, it might be more beneficial to focus on overall changes in transmembrane potential and calcium oscillations rather than on specific channels as it is likely that these changes, rather than the specific ion channels themselves, are what regulate development.

\section{CONCLUDING REMARKS}

Gaining a greater understanding of bioelectrical signaling will elucidate another complex pathway by which cells may coordinate development. This greater understanding of development is necessary to potentially open new avenues within medicine. Ion channel signaling is dependent on a network of interdependent ion channels and is not necessarily dependent on single individual types of channels. This means that pharmaceuticals that elicit changes in overall cell polarization rather than by acting on specific channels, could potentially regulate larger changes in morphogenesis which has not been previously possible. In regenerative medicine after trauma, for example, an understanding of bioelectric signaling may provide new avenues of directing tissue growth and healing. "Electroceuticals," devices or drugs that induce bioelectrical changes in tissues, are already being investigated as potential mechanisms in medicine to improve healing (Levin et al., 2019).

In summary, ion channels play an essential role in development with bioelectricity regulating cell death, the cell cycle, proliferation, cell polarity, migration, and the canonical developmental signaling pathways. A greater understanding of the mechanisms by which ion channels act will reveal new avenues in medicine by which developmental disorders may be treated.

\section{AUTHOR CONTRIBUTIONS}

LG wrote the first draft of the manuscript and created the figures. EB made suggestions for the content and edited the manuscript.

\section{ACKNOWLEDGMENTS}

We are grateful for funding from NIH-NIDCR R01DE025311 and NSF-IOS 1945916 and NSF-IOS 1354282 to EAB. EB would like to thank childcare providers for their heroic efforts during the Covid-19 pandemic. 


\section{REFERENCES}

Adams, C. J., Kopp, M. C., Larburu, N., Nowak, P. R., and Ali, M. M. U. (2019). Structure and Molecular Mechanism of ER Stress Signaling by the Unfolded Protein Response Signal Activator IRE1. Front. Mol. Biosci. 6, 11. doi:10.3389/ fmolb.2019.00011

Adams, D. S., Uzel, S. G. M., Akagi, J., Wlodkowic, D., Andreeva, V., Yelick, P. C., et al. (2016). Bioelectric Signalling via Potassium Channels: a Mechanism for Craniofacial Dysmorphogenesis in KCNJ2-Associated Andersen-Tawil Syndrome. J. Physiol. 594 (12), 3245-3270. doi:10.1113/jp271930

Amaral, M. D., Quaresma, M. C., and Pankonien, I. (2020). What Role Does CFTR Play in Development, Differentiation, Regeneration and Cancer? Int. J. Mol. Sci. 21 (9). doi:10.3390/ijms21093133

Amigorena, S., Choquet, D., Teillaud, J. L., Korn, H., and Fridman, W. H. (1990). Ion Channel Blockers Inhibit B Cell Activation at a Precise Stage of the G1 Phase of the Cell Cycle. Possible Involvement of K+ Channels. J. Immunol. 144 (6), 2038-2045.

Arrebola, F., Zabiti, S., Canizares, F. J., Cubero, M. A., Crespo, P. V., and Fernandez-Segura, E. (2005). Changes in Intracellular Sodium, Chlorine, and Potassium Concentrations in Staurosporine-Induced Apoptosis. J. Cel Physiol 204 (2), 500-507. doi:10.1002/jcp.20306

Atsuta, Y., Tomizawa, R. R., Levin, M., and Tabin, C. J. (2019). L-type VoltageGated Ca2+ Channel CaV1.2 Regulates Chondrogenesis during Limb Development. Proc. Natl. Acad. Sci. USA 116 (43), 21592-21601. doi:10. 1073/pnas.1908981116

Balaji, R., Bielmeier, C., Harz, H., Bates, J., Stadler, C., Hildebrand, A., et al. (2017). Calcium Spikes, Waves and Oscillations in a Large, Patterned Epithelial Tissue. Sci. Rep. 7, 42786. doi:10.1038/srep42786

Barel, O., Shalev, S. A., Ofir, R., Cohen, A., Zlotogora, J., Shorer, Z., et al. (2008). Maternally Inherited Birk Barel Mental Retardation Dysmorphism Syndrome Caused by a Mutation in the Genomically Imprinted Potassium Channel KCNK9. Am. J. Hum. Genet. 83 (2), 193-199. doi:10.1016/j.ajhg.2008.07.010

Belgacem, Y. H., and Borodinsky, L. N. (2011). Sonic Hedgehog Signaling Is Decoded by Calcium Spike Activity in the Developing Spinal Cord. Proc. Natl. Acad. Sci. U S A. 108 (11), 4482-4487. doi:10.1073/pnas.1018217108

Belus, M. T., Rogers, M. A., Elzubeir, A., Josey, M., Rose, S., Andreeva, V., et al. (2018). Kir2.1 Is Important for Efficient BMP Signaling in Mammalian Face Development. Dev. Biol. 444 (Suppl. 1), S297-S307. doi:10.1016/j.ydbio.2018. 02.012

Blackiston, D. J., McLaughlin, K. A., and Levin, M. (2009). Bioelectric Controls of Cell Proliferation: Ion Channels, Membrane Voltage and the Cell Cycle. Cell Cycle 8 (21), 3527-3536. doi:10.4161/cc.8.21.9888

Blaser, H., Reichman-Fried, M., Castanon, I., Dumstrei, K., Marlow, F. L., Kawakami, K., et al. (2006). Migration of Zebrafish Primordial Germ Cells: a Role for Myosin Contraction and Cytoplasmic Flow. Dev. Cel 11 (5), 613-627. doi:10.1016/j.devcel.2006.09.023

Bonora, M., and Pinton, P. (2014). The Mitochondrial Permeability Transition Pore and Cancer: Molecular Mechanisms Involved in Cell Death. Front. Oncol. 4, 302. doi:10.3389/fonc.2014.00302

Bortner, C. D., and Cidlowski, J. A. (2014). Ion Channels and Apoptosis in Cancer. Phil. Trans. R. Soc. B 369 (1638), 20130104. doi:10.1098/rstb.2013.0104

Bortner, C. D., Hughes, F. M., Jr., and Cidlowski, J. A. (1997). A Primary Role for $\mathrm{K}+$ and Na+ Efflux in the Activation of Apoptosis. J. Biol. Chem. 272 (51), 32436-32442. doi:10.1074/jbc.272.51.32436

Brodskiy, P. A., Wu, Q., Soundarrajan, D. K., Huizar, F. J., Chen, J., Liang, P., et al. (2019). Decoding Calcium Signaling Dynamics during Drosophila Wing Disc Development. Biophysical J. 116 (4), 725-740. doi:10.1016/j.bpj.2019.01.007

Campetelli, A., Bonazzi, D., and Minc, N. (2012). Electrochemical Regulation of Cell Polarity and the Cytoskeleton. Cytoskeleton (Hoboken) 69 (9), 601-612. doi: $10.1002 / \mathrm{cm} .21047$

Canales Coutino, B., and Mayor, R. (2021). Mechanosensitive Ion Channels in Cell Migration. Cells Dev 166, 203683. doi:10.1016/j.cdev.2021.203683

Catterall, W. A. (2011). Voltage-gated Calcium Channels. Cold Spring Harb Perspect. Biol. 3 (8), a003947. doi:10.1101/cshperspect.a003947

Cervera, J., Levin, M., and Mafe, S. (2020). Bioelectrical Coupling of Single-Cell States in Multicellular Systems. J. Phys. Chem. Lett. 11 (9), 3234-3241. doi:10. 1021/acs.jpclett.0c00641
Chen, Y. W., Chen, Y. F., Chen, Y. T., Chiu, W. T., and Shen, M. R. (2016). The STIM1-Orail Pathway of Store-Operated Ca2+ Entry Controls the Checkpoint in Cell Cycle G1/S Transition. Sci. Rep. 6, 22142. doi:10.1038/ srep22142

Chien, K. R., Abrams, J., Pfau, R. G., and Farber, J. L. (1977). Prevention by Chlorpromazine of Ischemic Liver Cell Death. Am. J. Pathol. 88 (3), 539-557.

Chong, J. X., McMillin, M. J., Shively, K. M., Beck, A. E., Marvin, C. T., Armenteros, J. R., et al. (2015). De Novo mutations in NALCN Cause a Syndrome Characterized by Congenital Contractures of the Limbs and Face, Hypotonia, and Developmental Delay. Am. J. Hum. Genet. 96 (3), 462-473. doi:10.1016/j.ajhg.2015.01.003

Choy, S. W., and Cheng, S. H. (2012). Hedgehog Signaling. Vitam Horm. 88, 1-23. doi:10.1016/b978-0-12-394622-5.00001-8

Cidad, P., Jimenez-Perez, L., Garcia-Arribas, D., Miguel-Velado, E., Tajada, S., Ruiz-McDavitt, C., et al. (2012). Kv1.3 Channels Can Modulate Cell Proliferation during Phenotypic Switch by an Ion-Flux Independent Mechanism. Arterioscler Thromb. Vasc. Biol. 32 (5), 1299-1307. doi:10.1161/ atvbaha.111.242727

Colomer, J., Lopez-Girona, A., Agell, N., and Bachs, O. (1994). Calmodulin Regulates the Expression of Cdks, Cyclins and Replicative Enzymes during Proliferative Activation of Human T Lymphocytes. Biochem. Biophys. Res. Commun. 200 (1), 306-312. doi:10.1006/bbrc.1994.1449

Cone, C. D., Jr., and Cone, C. M. (1976). Induction of Mitosis in Mature Neurons in central Nervous System by Sustained Depolarization. Science 192 (4235), 155-158. doi:10.1126/science.56781

Daane, J. M., Lanni, J., Rothenberg, I., Seebohm, G., Higdon, C. W., Johnson, S. L., et al. (2018). Bioelectric-calcineurin Signaling Module Regulates Allometric Growth and Size of the Zebrafish Fin. Sci. Rep. 8 (1), 10391. doi:10.1038/s41598018-28450-6

Dahal, G. R., Pradhan, S. J., and Bates, E. A. (2017). Inwardly Rectifying Potassium Channels Influence Drosophila wing Morphogenesis by Regulating Dpp Release. Development 144 (15), 2771-2783. doi:10.1242/dev.146647

Dahal, G. R., Rawson, J., Gassaway, B., Kwok, B., Tong, Y., Ptáček, L. J., et al. (2012). An Inwardly Rectifying K+ Channel Is Required for Patterning. Development 139 (19), 3653-3664. doi:10.1242/dev.078592

Dallaporta, B., Hirsch, T., Susin, S. A., Zamzami, N., Larochette, N., Brenner, C., et al. (1998). Potassium Leakage during the Apoptotic Degradation Phase. J. Immunol. 160 (11), 5605-5615.

Dargent, B., Arsac, C., Tricaud, N., and Couraud, F. (1996). Activation of Voltagedependent Sodium Channels in Cultured Cerebellar Poffule Cells Induces Neurotoxicity that Is Not Mediated by Glutamate Release. Neuroscience 73 (1), 209-216. doi:10.1016/0306-4522(95)00608-7

Davies, J. C., Alton, E. W. F. W., and Bush, A. (2007). Cystic Fibrosis. BMJ 335 (7632), 1255-1259. doi:10.1136/bmj.39391.713229.ad

DeCoursey, T. E., Chandy, K. G., Gupta, S., and Cahalan, M. D. (1984). Voltagegated K+ Channels in Human T Lymphocytes: a Role in Mitogenesis? Nature 307 (5950), 465-468. doi:10.1038/307465a0

Downie, B. R., Sanchez, A., Knotgen, H., Contreras-Jurado, C., Gymnopoulos, M., Weber, C., et al. (2008). Eag1 Expression Interferes with Hypoxia Homeostasis and Induces Angiogenesis in Tumors. J. Biol. Chem. 283 (52), 36234-36240. doi:10.1074/jbc.m801830200

Durant, F., Bischof, J., Fields, C., Morokuma, J., LaPalme, J., Hoi, A., et al. (2019). The Role of Early Bioelectric Signals in the Regeneration of Planarian Anterior/ Posterior Polarity. Biophysical J. 116 (5), 948-961. doi:10.1016/j.bpj.2019. 01.029

Durant, F., Morokuma, J., Fields, C., Williams, K., Adams, D. S., and Levin, M. (2017). Long-Term, Stochastic Editing of Regenerative Anatomy via Targeting Endogenous Bioelectric Gradients. Biophysical J. 112 (10), 2231-2243. doi:10. 1016/j.bpj.2017.04.011

Emmons-Bell, M., and Hariharan, I. K. (2021). Membrane Potential Regulates Hedgehog Signalling in the Drosophila wing Imaginal Disc. EMBO Rep. 22 (4), e51861. doi:10.15252/embr.202051861

Evans, J. H., and Sanderson, M. J. (1999). Intracellular Calcium Oscillations Induced by ATP in Airway Epithelial Cells. Am. J. Physiology-Lung Cell Mol. Physiol. 277 (1), L30-L41. doi:10.1152/ajplung.1999.277.1.130

Gemberling, M., Bailey, T. J., Hyde, D. R., and Poss, K. D. (2013). The Zebrafish as a Model for Complex Tissue Regeneration. Trends Genet. 29 (11), 611-620. doi:10.1016/j.tig.2013.07.003 
George, L. F., Pradhan, S. J., Mitchell, D., Josey, M., Casey, J., Belus, M. T., et al. (2019). Ion Channel Contributions to Wing Development in Drosophila melanogaster. G3 (Bethesda) 9 (4), 999-1008. doi:10.1534/g3.119.400028

Gierer, A., Berking, S., Bode, H., David, C. N., Flick, K., Hansmann, G., et al. (1972). Regeneration of hydra from Reaggregated Cells. Nat. New Biol. 239 (91), 98-101. doi:10.1038/newbio239098a0

Godin, L. M., Suzuki, S., Jacobs, C. R., Donahue, H. J., and Donahue, S. W. (2007). Mechanically Induced Intracellular Calcium Waves in Osteoblasts Demonstrate Calcium Fingerprints in Bone Cell Mechanotransduction. Biomech. Model. Mechanobiol 6 (6), 391-398. doi:10.1007/s10237-006-0059-5

Gosden, C., and Gosden, J. (1984). Fetal Abnormalities in Cystic Fibrosis Suggest a Deficiency in Proteolysis of Cholecystokinin. The Lancet 324 (8402), 541-546. doi:10.1016/s0140-6736(84)90765-7

Habela, C. W., Ernest, N. J., Swindall, A. F., and Sontheimer, H. (2009). Chloride Accumulation Drives Volume Dynamics Underlying Cell Proliferation and Migration. J. Neurophysiol. 101 (2), 750-757. doi:10.1152/jn.90840.2008

Habela, C. W., Olsen, M. L., and Sontheimer, H. (2008). ClC3 Is a Critical Regulator of the Cell Cycle in normal and Malignant Glial Cells. J. Neurosci. 28 (37), 9205-9217. doi:10.1523/jneurosci.1897-08.2008

Habela, C. W., and Sontheimer, H. (2007). Cytoplasmic Volume Condensation Is an Integral Part of Mitosis. Cell Cycle 6 (13), 1613-1620. doi:10.4161/cc.6.13. 4357

Hall, J. G. (2003). Twinning. The Lancet 362 (9385), 735-743. doi:10.1016/s01406736(03)14237-7

Harris, M. P. (2021). Bioelectric Signaling as a Unique Regulator of Development and Regeneration. Development 148 (10). doi:10.1242/dev.180794

Hartzell, C. A., Jankowska, K. I., Burkhardt, J. K., and Lewis, R. S. (2016). Calcium Influx through CRAC Channels Controls Actin Organization and Dynamics at the Immune Synapse. Elife 5. doi:10.7554/eLife.14850

Heo, J. S., Lee, M. Y., and Han, H. J. (2007). Sonic Hedgehog Stimulates Mouse Embryonic Stem Cell Proliferation by Cooperation of Ca2+/protein Kinase C and Epidermal Growth Factor Receptor as Well as Gli1 Activation. Stem Cells 25 (12), 3069-3080. doi:10.1634/stemcells.2007-0550

Hiramatsu, N., Chiang, W. C., Kurt, T. D., Sigurdson, C. J., and Lin, J. H. (2015). Multiple Mechanisms of Unfolded Protein Response-Induced Cell Death. Am. J. Pathol. 185 (7), 1800-1808. doi:10.1016/j.ajpath.2015.03.009

Huang, H., Liu, S., and Kornberg, T. B. (2019). Glutamate Signaling at Cytoneme Synapses. Science 363 (6430), 948-955. doi:10.1126/science.aat5053

Huang, Y. W., Chang, S. J., Harn, H. I., Huang, H. T., Lin, H. H., Shen, M. R., et al. (2015). Mechanosensitive Store-Operated Calcium Entry Regulates the Formation of Cell Polarity. J. Cel Physiol 230 (9), 2086-2097. doi:10.1002/ jcp. 24936

Hughes, F. M., Jr., Bortner, C. D., Purdy, G. D., and Cidlowski, J. A. (1997). Intracellular K+ Suppresses the Activation of Apoptosis in Lymphocytes. J. Biol. Chem. 272 (48), 30567-30576. doi:10.1074/jbc.272.48.30567

Humeau, J., Bravo-San Pedro, J. M., Vitale, I., Nunez, L., Villalobos, C., Kroemer, G., et al. (2018). Calcium Signaling and Cell Cycle: Progression or Death. Cell Calcium 70, 3-15. doi:10.1016/j.ceca.2017.07.006

Iovine, M. K., Higgins, E. P., Hindes, A., Coblitz, B., and Johnson, S. L. (2005). Mutations in Connexin43 (GJA1) Perturb Bone Growth in Zebrafish Fins. Dev. Biol. 278 (1), 208-219. doi:10.1016/j.ydbio.2004.11.005

Isner, T. O. Y., and Bates, E. A. (2021). Depolarization Induces BMP4 Release from Mouse Embryonic Palate Mesenchyme Cells. Co-submitted.

Justet, C., Chifflet, S., and Hernandez, J. A. (2019). Calcium Oscillatory Behavior and its Possible Role during Wound Healing in Bovine Corneal Endothelial Cells in Culture. Biomed. Res. Int. 2019, 8647121. doi:10.1155/2019/8647121

Kahl, C. R., and Means, A. R. (2004). Calcineurin Regulates Cyclin D1 Accumulation in Growth-Stimulated Fibroblasts. Mol. Biol. Cel 15 (4), 1833-1842. doi:10.1091/mbc.e03-10-0730

Kahl, C. R., and Means, A. R. (2003). Regulation of Cell Cycle Progression by Calcium/calmodulin-dependent Pathways. Endocr. Rev. 24 (6), 719-736. doi:10.1210/er.2003-0008

Kawano, S., Shoji, S., Ichinose, S., Yamagata, K., Tagami, M., and Hiraoka, M. (2002). Characterization of Ca2+ Signaling Pathways in Human Mesenchymal Stem Cells. Cell Calcium 32 (4), 165-174. doi:10.1016/s0143416002001240

Khandekar, A., Springer, S., Wang, W., Hicks, S., Weinheimer, C., Diaz-Trelles, R., et al. (2016). Notch-Mediated Epigenetic Regulation of Voltage-Gated
Potassium Currents. Circ. Res. 119 (12), 1324-1338. doi:10.1161/circresaha. 116.309877

Kiviluoto, S., Akl, H., Vervliet, T., Bultynck, G., Parys, J. B., Missiaen, L., et al. (2012). IP3 Receptor-Binding Partners in Cell-Death Mechanisms. Wiley Interdiscip. Rev. Membr. Transport Signaling 1 (2), 201-210. doi:10.1002/ wmts. 5

Klatt Shaw, D., Gunther, D., Jurynec, M. J., Chagovetz, A. A., Ritchie, E., and Grunwald, D. J. (2018). Intracellular Calcium Mobilization Is Required for Sonic Hedgehog Signaling. Dev. Cel 45 (4), 512-525 e5. doi:10.1016/j.devcel. 2018.04.013

Koike, T., Tanaka, S., Oda, T., and Ninomiya, T. (2000). Sodium Overload through Voltage-dependent $\mathrm{Na}(+)$ Channels Induces Necrosis and Apoptosis of Rat superior Cervical Ganglion Cells In Vitro. Brain Res. Bull. 51 (4), 345-355. doi:10.1016/s0361-9230(99)00246-4

Kono, T., Nishikori, T., Kataoka, H., Uchio, Y., Ochi, M., and Enomoto, K.-I. (2006). Spontaneous Oscillation and Mechanically Induced Calcium Waves in Chondrocytes. Cell Biochem. Funct. 24 (2), 103-111. doi:10.1002/cbf.1304

Kopan, R., and Ilagan, M. X. (2009). The Canonical Notch Signaling Pathway: Unfolding the Activation Mechanism. Cell 137 (2), 216-233. doi:10.1016/j.cell. 2009.03.045

Kruman, I., Guo, Q., and Mattson, M. P. (1998). Calcium and Reactive Oxygen Species Mediate Staurosporine-Induced Mitochondrial Dysfunction and Apoptosis in PC12 Cells. J. Neurosci. Res. 51 (3), 293-308. doi:10.1002/(sici) 1097-4547(19980201)51:3<293::aid-jnr3>3.0.co;2-b

Lang, F., and Stournaras, C. (2014). Ion Channels in Cancer: Future Perspectives and Clinical Potential. Philos. Trans. R. Soc. Lond. B Biol. Sci. 369 (1638), 20130108. doi:10.1098/rstb.2013.0108

Lang, F., Shumilina, E., Ritter, M., Gulbins, E., Vereninov, A., and Huber, S. M. (2006). Ion Channels and Cell Volume in Regulation of Cell Proliferation and Apoptotic Cell Death. Contrib. Nephrol. 152, 142-160. doi:10.1159/ 000096321

Larson, J. E., and Cohen, J. C. (2005). Developmental Paradigm for Early Features of Cystic Fibrosis. Pediatr. Pulmonol. 40 (5), 371-377. doi:10.1002/ppul.20169

Larson, J. E., Delcarpio, J. B., Farberman, M. M., Morrow, S. L., and Cohen, J. C. (2000). CFTR Modulates Lung Secretory Cell Proliferation and Differentiation. Am. J. Physiology-Lung Cell Mol. Physiol. 279 (2), L333-L341. doi:10.1152/ ajplung.2000.279.2.1333

Larson, J. E., Morrow, S. L., Delcarpio, J. B., Bohm, R. P., Ratterree, M. S., Blanchard, J. L., et al. (2000). Gene Transfer into the Fetal Primate: Evidence for the Secretion of Transgene Product. Mol. Ther. 2 (6), 631-639. doi:10.1006/mthe.2000.0209

Lazzari-Dean, J. R., Gest, A. M., and Miller, E. W. (2019). Optical Estimation of Absolute Membrane Potential Using Fluorescence Lifetime Imaging. Elife 8. doi:10.7554/eLife.44522

Lee, S. H., Park, Y., Song, M., Srikanth, S., Kim, S., Kang, M. K., et al. (2016). Orai1 Mediates Osteogenic Differentiation via BMP Signaling Pathway in Bone Marrow Mesenchymal Stem Cells. Biochem. Biophys. Res. Commun. 473 (4), 1309-1314. doi:10.1016/j.bbrc.2016.04.068

Lee, Y. S., Sayeed, M. M., and Wurster, R. D. (1993). Inhibition of Cell Growth by $\mathrm{K}+$ Channel Modulators Is Due to Interference with Agonist-Induced Ca2+ Release. Cell Signal 5 (6), 803-809. doi:10.1016/0898-6568(93)90041-j

Levin, M. (2021). Bioelectric Signaling: Reprogrammable Circuits Underlying Embryogenesis, Regeneration, and Cancer. Cell 184 (8), 1971-1989. doi:10. 1016/j.cell.2021.02.034

Levin, M. (2014). Molecular Bioelectricity: How Endogenous Voltage Potentials Control Cell Behavior and Instruct Pattern Regulation In Vivo. MBoC 25 (24), 3835-3850. doi:10.1091/mbc.e13-12-0708

Levin, M., Selberg, J., and Rolandi, M. (2019). Endogenous Bioelectrics in Development, Cancer, and Regeneration: Drugs and Bioelectronic Devices as Electroceuticals for Regenerative Medicine. iScience 22, 519-533. doi:10. 1016/j.isci.2019.11.023

Li, A., Cho, J.-H., Reid, B., Tseng, C.-C., He, L., Tan, P., et al. (2018). Calcium Oscillations Coordinate Feather Mesenchymal Cell Movement by $\mathrm{SHH}$ Dependent Modulation of gap junction Networks. Nat. Commun. 9 (1), 5377. doi:10.1038/s41467-018-07661-5

Mammoto, T., and Ingber, D. E. (2010). Mechanical Control of Tissue and Organ Development. Development 137 (9), 1407-1420. doi:10.1242/dev.024166 
Martikainen, P., Kyprianou, N., Tucker, R. W., and Isaacs, J. T. (1991), Programmed Death of Nonproliferating Androgen-independent Prostatic Cancer Cells. Cancer Res. 51(17), 4693-4700.

Masotti, A., Uva, P., Davis-Keppen, L., Basel-Vanagaite, L., Cohen, L., Pisaneschi, E., et al. (2015). Keppen-Lubinsky Syndrome Is Caused by Mutations in the Inwardly Rectifying K+ Channel Encoded by KCNJ6. Am. J. Hum. Genet. 96 (2), 295-300. doi:10.1016/j.ajhg.2014.12.011

Millership, J. E., Devor, D. C., Hamilton, K. L., Balut, C. M., Bruce, J. I., and Fearon, I. M. (2011). Calcium-activated K+ Channels Increase Cell Proliferation Independent of K+ Conductance. Am. J. Physiol. Cel Physiol 300 (4), C792-C802. doi:10.1152/ajpcell.00274.2010

Miyazaki, H., Shiozaki, A., Niisato, N., Ohsawa, R., Itoi, H., Ueda, Y., et al. (2008). Chloride Ions Control the G1/S Cell-Cycle Checkpoint by Regulating the Expression of P21 through a P53-independent Pathway in Human Gastric Cancer Cells. Biochem. Biophys. Res. Commun. 366 (2), 506-512. doi:10.1016/j. bbrc.2007.11.144

Nakagawa, T., Zhu, H., Morishima, N., Li, E., Xu, J., Yankner, B. A., et al. (2000). Caspase-12 Mediates Endoplasmic-reticulum-specific Apoptosis and Cytotoxicity by Amyloid-Beta. Nature 403 (6765), 98-103. doi:10.1038/47513

Narciso, C., Wu, Q., Brodskiy, P., Garston, G., Baker, R., Fletcher, A., et al. (2015). Patterning of Wound-Induced Intercellular Ca2+flashes in a Developing Epithelium. Phys. Biol. 12 (5), 056005. doi:10.1088/1478-3975/12/5/056005

Nathanson, M. H. (1994). Cellular and Subcellular Calcium Signaling in Gastrointestinal Epithelium. Gastroenterology 106 (5), 1349-1364. doi:10. 1016/0016-5085(94)90030-2

Neglia, J. P., FitzSimmons, S. C., Maisonneuve, P., Schoni, M. H., Schoni-Affolter, F., Corey, M., et al. (1995). The Risk of Cancer Among Patients with Cystic Fibrosis. Cystic Fibrosis and Cancer Study Group. N. Engl. J. Med. 332 (8), 494-499. doi:10.1056/nejm199502233320803

Nihei, O. K., Campos de Carvalho, A. C., Spray, D. C., Savino, W., and Alves, L. A. (2003). A Novel Form of Cellular Communication Among Thymic Epithelial Cells: Intercellular Calcium Wave Propagation. Am. J. Physiology-Cell Physiol. 285 (5), C1304-C1313. doi:10.1152/ajpcell.00568.2002

Nusrat, A., Giry, M., Turner, J. R., Colgan, S. P., Parkos, C. A., Carnes, D., et al. (1995). Rho Protein Regulates Tight Junctions and Perijunctional Actin Organization in Polarized Epithelia. Proc. Natl. Acad. Sci. U S A. 92 (23), 10629-10633. doi:10.1073/pnas.92.23.10629

Ohno, Y., and Otaki, J. M. (2015). Spontaneous Long-Range Calcium Waves in Developing Butterfly Wings. BMC Dev. Biol. 15, 17. doi:10.1186/s12861-0150067-8

Okada, Y., Maeno, E., Shimizu, T., Manabe, K., Mori, S., and Nabekura, T. (2004). Dual Roles of Plasmalemmal Chloride Channels in Induction of Cell Death. Pflugers Arch. 448 (3), 287-295. doi:10.1007/s00424-004-1276-3

Okada, Y., Shimizu, T., Maeno, E., Tanabe, S., Wang, X., and Takahashi, N. (2006). Volume-sensitive Chloride Channels Involved in Apoptotic Volume Decrease and Cell Death. J. Membr. Biol. 209 (1), 21-29. doi:10.1007/s00232-005-0836-6

Orrenius, S., Zhivotovsky, B., and Nicotera, P. (2003). Regulation of Cell Death: the Calcium-Apoptosis Link. Nat. Rev. Mol. Cel Biol 4 (7), 552-565. doi:10.1038/ nrm1150

Osawa, H., Ohnishi, H., Takano, K., Noguti, T., Mashima, H., Hoshino, H., et al. (2006). Sonic Hedgehog Stimulates the Proliferation of Rat Gastric Mucosal Cells through ERK Activation by Elevating Intracellular Calcium Concentration. Biochem. Biophys. Res. Commun. 344 (2), 680-687. doi:10. 1016/j.bbrc.2006.03.188

Ovsepian, S. V. (2017). The Birth of the Synapse. Brain Struct. Funct. 222 (8), 3369-3374. doi:10.1007/s00429-017-1459-2

Ovsepian, S. V., and Vesselkin, N. P. (2014). Wiring Prior to Firing: the Evolutionary Rise of Electrical and Chemical Modes of Synaptic Transmission. Rev. Neurosci. 25 (6), 821-832. doi:10.1515/revneuro-2014-0037

Ovsepian, S. V., O'Leary, V. B., and Vesselkin, N. P. (2020). Evolutionary Origins of Chemical Synapses. Vitam Horm. 114, 1-21. doi:10.1016/bs.vh.2020.04.009

Pai, V. P., Aw, S., Shomrat, T., Lemire, J. M., and Levin, M. (2012). Transmembrane Voltage Potential Controls Embryonic Eye Patterning in Xenopus laevis. Development 139 (2), 313-323. doi:10.1242/dev.073759

Perathoner, S., Daane, J. M., Henrion, U., Seebohm, G., Higdon, C. W., Johnson, S. L., et al. (2014). Bioelectric Signaling Regulates Size in Zebrafish Fins. Plos Genet. 10 (1), e1004080. doi:10.1371/journal.pgen.1004080
Perez-Riera, A. R., Barbosa-Barros, R., Samesina, N., Pastore, C. A., Scanavacca, M., Daminello-Raimundo, R., et al. (2020). Andersen-Tawil Syndrome: A Comprehensive Review. Cardiol. Rev. 29(4):165-177. doi:10.1097/CRD. 0000000000000326

Periz, G., and Fortini, M. E. (1999). Ca(2+)-ATPase Function Is Required for Intracellular Trafficking of the Notch Receptor in Drosophila. EMBO J. 18 (21), 5983-5993. doi:10.1093/emboj/18.21.5983

Phipps, L. S., Marshall, L., Dorey, K., and Amaya, E. (2020). Model Systems for Regeneration: Xenopus. Development 147 (6). doi:10.1242/dev.180844

Pinet, K., Deolankar, M., Leung, B., and McLaughlin, K. A. (2019). Adaptive Correction of Craniofacial Defects in Pre-metamorphic Xenopus laevis Tadpoles Involves Thyroid Hormone-independent Tissue Remodeling. Development 146 (14), dev175893. doi:10.1242/dev.175893

Plaster, N. M., Tawil, R., Tristani-Firouzi, M., Canún, S., Bendahhou, S., Tsunoda, A., et al. (2001). Mutations in Kir2.1 Cause the Developmental and Episodic Electrical Phenotypes of Andersen's Syndrome. Cell 105 (4), 511-519. doi:10. 1016/s0092-8674(01)00342-7

Prevarskaya, N., Skryma, R., and Shuba, Y. (2018). Ion Channels in Cancer: Are Cancer Hallmarks Oncochannelopathies? Physiol. Rev. 98 (2), 559-621. doi:10. 1152/physrev.00044.2016

Rajasekaran, S. A., Palmer, L. G., Moon, S. Y., Soler, A. P., Apodaca, G. L., Harper, J. F., et al. (2001). Na,K-ATPase Activity Is Required for Formation of Tight Junctions, Desmosomes, and Induction of Polarity in Epithelial Cells. Mol. Biol. Cel 12 (12), 3717-3732. doi:10.1091/mbc.12.12.3717

Ramachandran, K. V., Hennessey, J. A., Barnett, A. S., Yin, X., Stadt, H. A., Foster, E., et al. (2013). Calcium Influx through L-type CaV1.2 Ca2+ Channels Regulates Mandibular Development. J. Clin. Invest. 123 (4), 1638-1646. doi: $10.1172 /$ jci66903

Rand, M. D., Lindblom, A., Carlson, J., Villoutreix, B. O., and Stenflo, J. (1997). Calcium Binding to Tandem Repeats of EGF-like Modules. Expression and Characterization of the EGF-like Modules of Human Notch-1 Implicated in Receptor-Ligand Interactions. Protein Sci. 6 (10), 2059-2071. doi:10.1002/pro. 5560061002

Rapetti-Mauss, R., Berenguier, C., Allegrini, B., and Soriani, O. (2020). Interplay between Ion Channels and the Wnt/beta-Catenin Signaling Pathway in Cancers. Front. Pharmacol. 11, 525020. doi:10.3389/fphar.2020.525020

Rapetti-Mauss, R., Bustos, V., Thomas, W., McBryan, J., Harvey, H., Lajczak, N., et al. (2017). Bidirectional KCNQ1:beta-Catenin Interaction Drives Colorectal Cancer Cell Differentiation. Proc. Natl. Acad. Sci. U S A. 114 (16), 4159-4164. doi:10.1073/pnas.1702913114

Reddien, P. W., and Alvarado, A. S. (2004). Fundamentals of Planarian Regeneration. Annu. Rev. Cel Dev. Biol. 20, 725-757. doi:10.1146/annurev. cellbio.20.010403.095114

Restrepo, S., and Basler, K. (2016). Drosophila wing Imaginal Discs Respond to Mechanical Injury via Slow InsP3R-Mediated Intercellular Calcium Waves. Nat. Commun. 7, 12450. doi:10.1038/ncomms 12450

Rizzuto, R., Pinton, P., Ferrari, D., Chami, M., Szabadkai, G., Magalhães, P. J., et al. (2003). Calcium and Apoptosis: Facts and Hypotheses. Oncogene 22 (53), 8619-8627. doi:10.1038/sj.onc. 1207105

Rogers, K. W., and Schier, A. F. (2011). Morphogen Gradients: from Generation to Interpretation. Annu. Rev. Cel Dev. Biol. 27, 377-407. doi:10.1146/annurevcellbio-092910-154148

Roti, G., Carlton, A., Ross, K. N., Markstein, M., Pajcini, K., Su, A. H., et al. (2013). Complementary Genomic Screens Identify SERCA as a Therapeutic Target in NOTCH1 Mutated Cancer. Cancer Cell 23 (3), 390-405. doi:10.1016/j.ccr.2013. 01.015

Roy, S., and Gatien, S. (2008). Regeneration in Axolotls: a Model to Aim for!. Exp. Gerontol. 43 (11), 968-973. doi:10.1016/j.exger.2008.09.003

Ruiz, A., Matute, C., and Alberdi, E. (2010). Intracellular Ca2+ Release through Ryanodine Receptors Contributes to AMPA Receptor-Mediated Mitochondrial Dysfunction and ER Stress in Oligodendrocytes. Cell Death Dis 1, e54. doi:10. 1038/cddis.2010.31

Sachs, H. G., Stambrook, P. J., and Ebert, J. D. (1974). Changes in Membrane Potential during the Cell Cycle. Exp. Cel Res 83 (2), 362-366. doi:10.1016/00144827(74)90350-4

Schanne, F. A., Pfau, R. G., and Farber, J. L. (1980). Galactosamine-induced Cell Death in Primary Cultures of Rat Hepatocytes. Am. J. Pathol. 100 (1), 25-38. 
Sehgal, P., Szalai, P., Olesen, C., Praetorius, H. A., Nissen, P., Christensen, S. B., et al. (2017). Inhibition of the Sarco/endoplasmic Reticulum (ER) Ca(2+)ATPase by Thapsigargin Analogs Induces Cell Death via ER Ca(2+) Depletion and the Unfolded Protein Response. J. Biol. Chem. 292 (48), 19656-19673. doi:10.1074/jbc.m117.796920

Shiozaki, A., Otsuji, E., and Marunaka, Y. (2011). Intracellular Chloride Regulates the G(1)/S Cell Cycle Progression in Gastric Cancer Cells. World J. Gastrointest. Oncol. 3 (8), 119-122. doi:10.4251/wjgo.v3.i8.119

Short, A. D., Bian, J., Ghosh, T. K., Waldron, R. T., Rybak, S. L., and Gill, D. L. (1993). Intracellular Ca2+ Pool Content Is Linked to Control of Cell Growth. Proc. Natl. Acad. Sci. U S A. 90 (11), 4986-4990. doi:10.1073/pnas.90.11.4986

Simons, C., Rash, L. D., Crawford, J., Ma, L., Cristofori-Armstrong, B., Miller, D., et al. (2015). Mutations in the Voltage-Gated Potassium Channel Gene KCNH1 Cause Temple-Baraitser Syndrome and Epilepsy. Nat. Genet. 47 (1), 73-77. doi: $10.1038 /$ ng. 3153

Slusarski, D. C., and Pelegri, F. (2007). Calcium Signaling in Vertebrate Embryonic Patterning and Morphogenesis. Dev. Biol. 307 (1), 1-13. doi:10.1016/j.ydbio. 2007.04.043

Smith-Bolton, R. K., Worley, M. I., Kanda, H., and Hariharan, I. K. (2009). Regenerative Growth in Drosophila Imaginal Discs Is Regulated by Wingless and Myc. Dev. Cel 16 (6), 797-809. doi:10.1016/j.devcel.2009.04.015

Song, S., Babicheva, A., Zhao, T., Ayon, R. J., Rodriguez, M., Rahimi, S., et al. (2020). Notch Enhances $\mathrm{Ca}(2+)$ Entry by Activating Calcium-Sensing Receptors and Inhibiting Voltage-Gated K(+) Channels. Am. J. Physiol. Cel Physiol 318 (5), C954-C68. doi:10.1152/ajpcell.00487.2019

Splawski, I., Timothy, K. W., Decher, N., Kumar, P., Sachse, F. B., Beggs, A. H., et al. (2005). Severe Arrhythmia Disorder Caused by Cardiac L-type Calcium Channel Mutations. Proc. Natl. Acad. Sci. 102 (23), 8089-8096. discussion 6-8. doi:10.1073/pnas.0502506102

Splawski, I., Timothy, K. W., Sharpe, L. M., Decher, N., Kumar, P., Bloise, R., et al. (2004). Ca(V)CaV1.2 Calcium Channel Dysfunction Causes a Multisystem Disorder Including Arrhythmia and Autism. Cell 119 (1), 19-31. doi:10.1016/j. cell.2004.09.011

Srivastava, P., Kane, A., Harrison, C., and Levin, M. (2021). A Meta-Analysis of Bioelectric Data in Cancer, Embryogenesis, and Regeneration. Bioelectricity 3 (No. 1), 42-67. doi:10.1089/bioe.2019.0034

Stewart, T. A., and Davis, F. M. (2019). An Element for Development: Calcium Signaling in Mammalian Reproduction and Development. Biochim. Biophys. Acta (Bba) - Mol. Cel Res. 1866 (7), 1230-1238. doi:10.1016/j.bbamcr.2019. 02.016

Stillwell, E. F., Cone, C. M., and Cone, C. D., Jr (1973). Stimulation of DNA Synthesis in CNS Neurones by Sustained Depolarisation. Nat. New Biol. 246 (152), 110-111. doi:10.1038/newbio246110a0

Strubberg, A. M., Liu, J., Walker, N. M., Stefanski, C. D., MacLeod, R. J., Magness, S. T., et al. (2018). Cftr Modulates Wnt/beta-Catenin Signaling and Stem Cell Proliferation in Murine Intestine. Cell Mol Gastroenterol Hepatol 5 (3), 253-271. doi:10.1016/j.jcmgh.2017.11.013

Suisse, A., and Treisman, J. E. (2019). Reduced SERCA Function Preferentially Affects Wnt Signaling by Retaining E-Cadherin in the Endoplasmic Reticulum. Cell Rep 26 (2), 322-329 e3. doi:10.1016/j.celrep.2018.12.049

Sundelacruz, S., Levin, M., and Kaplan, D. L. (2009). Role of Membrane Potential in the Regulation of Cell Proliferation and Differentiation. Stem Cel Rev Rep 5 (3), 231-246. doi:10.1007/s12015-009-9080-2

Tawil, R., Ptacek, L. J., Pavlakis, S. G., DeVivo, D. C., Penn, A. S., Özdemir, C., et al. (1994). Andersen's Syndrome: Potassium-Sensitive Periodic Paralysis, Ventricular Ectopy, and Dysmorphic Features. Ann. Neurol. 35 (3), 326-330. doi:10.1002/ana.410350313

Tomono, M., Toyoshima, K., Ito, M., Amano, H., and Kiss, Z. (1998). Inhibitors of Calcineurin Block Expression of Cyclins A and E Induced by Fibroblast Growth Factor in Swiss 3T3 Fibroblasts. Arch. Biochem. Biophys. 353 (2), 374-378. doi:10.1006/abbi.1998.0667

Tsutsumi, M., Inoue, K., Denda, S., Ikeyama, K., Goto, M., and Denda, M. (2009). Mechanical-stimulation-evoked Calcium Waves in Proliferating and Differentiated Human Keratinocytes. Cell Tissue Res 338 (1), 99-106. doi:10. 1007/s00441-009-0848-0
Uhlén, P., and Fritz, N. (2010). Biochemistry of Calcium Oscillations. Biochem. Biophysical Res. Commun. 396 (1), 28-32. doi:10.1016/j.bbrc. 2010.02.117

Uhrenholt, T. R., Domeier, T. L., and Segal, S. S. (2007). Propagation of Calcium Waves along Endothelium of Hamster Feed Arteries. Am. J. Physiology-Heart Circulatory Physiol. 292 (3), H1634-H1640. doi:10. 1152/ajpheart.00605.2006

Urrego, D., Tomczak, A. P., Zahed, F., Stuhmer, W., and Pardo, L. A. (2014), Potassium Channels in Cell Cycle and Cell Proliferation. Philos. Trans. R. Soc. Lond. B Biol. Sci. 369 (1638), 20130094. doi:10.1098/rstb.2013.0094

Vandenberg, L. N., Adams, D. S., and Levin, M. (2012). Normalized Shape and Location of Perturbed Craniofacial Structures in the Xenopus Tadpole Reveal an Innate Ability to Achieve Correct Morphology. Dev. Dyn. 241 (5), 863-878. doi:10.1002/dvdy.23770

Vandenberg, L. N., Morrie, R. D., and Adams, D. S. (2011). V-ATPase-dependent Ectodermal Voltage and $\mathrm{pH}$ Regionalization Are Required for Craniofacial Morphogenesis. Dev. Dyn. 240 (8), 1889-1904. doi:10.1002/dvdy.22685

Wallingford, J. B., Ewald, A. J., Harland, R. M., and Fraser, S. E. (2001). Calcium Signaling during Convergent Extension in Xenopus. Curr. Biol. 11 (9), 652-661. doi:10.1016/s0960-9822(01)00201-9

Webb, S. E., and Miller, A. L. (2006). Ca2+ Signaling and Early Embryonic Patterning during the Blastula and Gastrula Periods of Zebrafish and Xenopus Development. Biochim. Biophys. Acta (Bba) - Mol. Cel Res. 1763 (11), 1192-1208. doi:10.1016/j.bbamcr.2006.08.004

Williams, G. S., Boyman, L., Chikando, A. C., Khairallah, R. J., and Lederer, W. J. (2013). Mitochondrial Calcium Uptake. Proc. Natl. Acad. Sci. U S A. 110 (26), 10479-10486. doi:10.1073/pnas.1300410110

Wonderlin, W. F., Woodfork, K. A., and Strobl, J. S. (1995). Changes in Membrane Potential during the Progression of MCF-7 Human Mammary Tumor Cells through the Cell Cycle. J. Cel Physiol 165 (1), 177-185. doi:10.1002/jcp. 1041650121

Xu, B., Mao, J., Wang, L., Zhu, L., Li, H., Wang, W., et al. (2010). ClC-3 Chloride Channels Are Essential for Cell Proliferation and Cell Cycle Progression in Nasopharyngeal Carcinoma Cells. Acta Biochim. Biophys. Sin (Shanghai). 42 (6), 370-380. doi:10.1093/abbs/gmq031

Xu, N., Luo, K. Q., and Chang, D. C. (2003). Ca2+ Signal Blockers Can Inhibit M/A Transition in Mammalian Cells by Interfering with the Spindle Checkpoint. Biochem. Biophys. Res. Commun. 306 (3), 737-745. doi:10.1016/s0006-291x(03) 01061-1

Yokota, Y., Nakajima, H., Wakayama, Y., Muto, A., Kawakami, K., Fukuhara, S., et al. (2015). Endothelial Ca 2+ Oscillations Reflect VEGFR SignalingRegulated Angiogenic Capacity In Vivo. Elife 4. doi:10.7554/eLife.08817

Yu, S. P. (2003). Regulation and Critical Role of Potassium Homeostasis in Apoptosis. Prog. Neurobiol. 70 (4), 363-386. doi:10.1016/s0301-0082(03) 00090-x

Zhivotovsky, B., and Orrenius, S. (2011). Calcium and Cell Death Mechanisms: a Perspective from the Cell Death Community. Cell Calcium 50 (3), 211-221. doi:10.1016/j.ceca.2011.03.003

Conflict of Interest: The authors declare that the research was conducted in the absence of any commercial or financial relationships that could be construed as a potential conflict of interest.

Publisher's Note: All claims expressed in this article are solely those of the authors and do not necessarily represent those of their affiliated organizations, or those of the publisher, the editors and the reviewers. Any product that may be evaluated in this article, or claim that may be made by its manufacturer, is not guaranteed or endorsed by the publisher.

Copyright ( 2022 George and Bates. This is an open-access article distributed under the terms of the Creative Commons Attribution License (CC BY). The use, distribution or reproduction in other forums is permitted, provided the original author(s) and the copyright owner(s) are credited and that the original publication in this journal is cited, in accordance with accepted academic practice. No use, distribution or reproduction is permitted which does not comply with these terms. 